Revista "Política y Estrategia" № 135, 2020, pp. 21-72

ISSN 0716-7415 (versión impresa) - ISSN 0719-8027 (versión en línea)

Academia Nacional de Estudios Políticos y Estratégicos

¿Qué cambios se están produciendo en las Fuerzas Armadas latinoamericanas? José Manuel Ugarte

\title{
¿QUÉ CAMBIOS SE ESTÁN PRODUCIENDO EN LAS FUERZAS ARMADAS LATINOAMERICANAS? $\infty$
}

\section{RESUMEN}

Las Fuerzas Armadas latinoamericanas son una realidad dinámica más en una región en constante cambio. Mientras en Latinoamérica el antiguo predominio de gobiernos de centro-izquierda y de izquierda ha cedido paso a una gran mayoría de gobiernos conservadores, la integración subregional y regional aparece en franca decadencia, surge entre los Estados entre sí y dentro de ellos un enrarecido clima de lucha ideológica, y la prolongada paz de la región ya no parece un bien que hay que dar por sobreentendido, parece inevitable que ese nuevo clima regional impacte en las Fuerzas Armadas. En este ámbito puede observarse un claro retroceso del control civil o conducción política de la defensa en diversos grados en la mayoría de los Estados, pudiendo también advertirse una creciente tendencia al involucramiento de las referidas Fuerzas en roles no tradicionales militares, particularmente en seguridad interior, y la búsqueda o incluso el logro de cierta autonomía. Mientras el equipamiento y el gasto militar permanecen sin mayores alteraciones, algunos países se han reequipado significativamente, sin que ello se haya traducido hasta el momento en alteraciones o amenazas a la paz.
\end{abstract}

JOSÉ MANUEL UGARTE•

Los máximos interrogantes parecen radicar en las limitaciones y desafios en materia de control civil y en los efectos del creciente empleo de las Fuerzas Armadas en seguridad interior tanto en materia política-respecto del control civil-, así como el eventual debilitamiento de la democracia y del respeto de los derechos humanos en los países de la región, como también en los nunca descartables efectos que la polarización política pueda producir en materia de tensiones internacionales en la región.

Palabras clave: Control; integración; polarización; tensión, democracia.

× Fecha de recepción: 280320 - Fecha de aceptación: 130820.

- Doctor de la Universidad de Buenos Aires (área Derecho Administrativo) abogado y especialista en Derecho Administrativo y Administración Pública por la referida Universidad, en la que es profesor en grado y postgrado. Asimismo, se desempeña como profesor en la Universidad Católica de Santiago del Estero (DABA) así como profesor de postgrado en la Universidad Abierta Interamericana, profesor en la Escuela del Cuerpo de Abogados del Estado y profesor en la Diplomatura de Empleo Público organizada por la Procuración General de la Ciudad de Buenos Aires y la Universidad del Museo Social Argentino. manuguart@gmail.com, imugarte@derecho.uba.ar.de ORCID ID https://orcid.org/0000-0003-3300-4529. 


\title{
WHAT CHANGES ARE TAKING PLACE IN THE LATIN AMERICAN
} ARMED FORCES?

\begin{abstract}
The Latin American Armed Forces are one more dynamic reality in a constantly changing region. While in Latin America the former predominance of center-left and left-wing governments has given way to a large majority of conservative governments, subregional and regional integration appears in clear decline, a climate of ideological struggle arises between the states among themselves and within them, and the prolonged peace in the region no longer seems a good to be taken for granted, it seems inevitable that this new regional climate will impact the Armed Forces. In this area, a clear decline of civil control or political leadership of defense can be observed to various degrees in most States, and a growing tendency to involve the aforementioned forces in non-traditional military roles, particularly in internal security, can also be observed, as well as the search for autonomy by the aforementioned Forces. While military equipment and spending remain almost unchanged, some countries have been significantly re-equipped, without this having produced, at least for the moment, threats to peace.
\end{abstract}

The main questions seem to lie in the limitations and challenges in terms of civilian control and in the effects of the growing use of the Armed Forces in internal security, both in political matters - regarding civilian control - and in the human rights of the population, as well as the eventual weakening of democracy and respect for human rights in the countries of the region, as also in the never ruled out effects that political polarization may produce in terms of international tensions in the region.

Key words: Control; integration; polarization; tension; democracy.

\section{QUE ALTERAÇÕES ESTÃO SENDO PRODUZIDAS NAS FORÇAS ARMADAS LATIN AMERICANAS?}

\begin{abstract}
RESUMO
As Forças Armadas da América Latina são mais uma realidade dinâmica em uma região em constante mudança. Enquanto na América Latina a antiga predominância de governos de centro esquerda e de esquerda deu lugar a uma grande maioria de governos conservadores, a integração sub-regional e regional aparece em franco declínio, um raro clima de luta ideológica surge entre os estados. e a paz prolongada na
\end{abstract}


região não parece mais uma situacão definitiva. Parece inevitável que esse novo clima regional tenha impacto nas Forças Armadas. Nesta área, um claro declínio no controle civil ou liderança política de defesa pode ser observado em vários graus na maioria dos Estados, e uma tendência crescente de envolver as forças mencionadas em papéis militares não tradicionais, particularmente em segurança interna, como também a busca ou até a conquista pelas Forças Armadas de uma certa autonomia. Embora o equipamento e os gastos militares permaneçam inalterados, alguns paises foram significativamente equipados, sem terem sido produzidas até o momento alterações ou ameaças à paz.

As principais questões parecem estar nas limitações e desafios no campo do controle civil e nos efeitos do crescente uso das Forças Armadas na segurança interna, tanto em questões políticas - em relação ao controle civil, quanto no eventual enfraquecimento da democracia e do respeito. direitos humanos nos países da região, bem como nos efeitos nunca descartados que a polarização política pode produzir em termos de tensões internacionais na região.

Palavras-chave: Controle; integração; polarização; tensão; democracia.

\section{Introducción. El nuevo panorama político latinoamericano}

Pocos hubieran podido prever el escenario latinoamericano actual hace solo quince años. La mayoría que representaban los gobiernos de centroizquierda en la región ha cedido ante una muy clara mayoría de gobiernos conservadores; la integración regional y subregional, en constante progreso por espacio de cuatro décadas, se encuentra en crisis, y el viejo sueño de una Sudamérica integrada a la manera de la Unión Europea parece concluido.

La integración sudamericana que fuera impulsada con los procesos subregionales de integración Comunidad Andina de Naciones (CAN) y Mercado Común del Sur MERCOSUR, que parecieron culminar con la creación de la Unión de Naciones Suramericanas -UNASURel 23 de mayo de 2008, destinada a complementar y fortalecer la integración económica

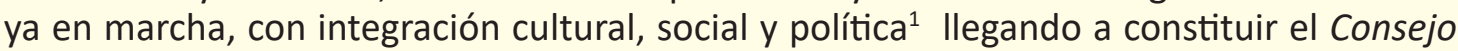
de Defensa Suramericano como “...ámbito de consulta, cooperación y coordinación en materia de defensa..." ${ }^{\prime 2}$, primer órgano sudamericano en materia de defensa integrado exclusivamente por países de la subregión, que habría de funcionar activamente por

1 Tratado Constitutivo de la Unión de Naciones Suramericanas, Brasilia, 23 de mayo de 2008, artículo 2으, obtenido de Universidad Nacional de La Plata, [En línea] Consultado el 15 de marzo de 2020, disponible en http://sedici.unlp.edu.ar/bitstream/handle/10915/45568/UNASUR_-_Tratado_Constitutivo_de_la_ Uni\%C3\%B3n_de_Naciones_Suramericanas_10_p._pdf?sequence=3

2 Artículo 10 de la Decisión para la Creación del Consejo de Defensa Suramericano de UNASUR, adoptada en la Cumbre Extraordinaria de UNASUR celebrada en Costa do Sauípe, Bahía, 16 de diciembre de 2008. 
espacio de nueve años, ha sufrido el retroceso representado por la virtual extinción de UNASUR.

Permanece fundamentalmente incólume el Sistema de Integración Centroamericana (SICA), creado en 1991 como Organización de los Estados Centroamericanos (ODECA), siendo los Estados centroamericanos los únicos vinculados entre sí por un acuerdo de seguridad externa e interna, el Tratado Marco de Seguridad Democrática en Centroamérica $(1995)^{3}$.

Hasta 2015 podría advertirse en Latinoamérica un clima de avance en materia de integración subregional y de construcción de paz, que incluyó como hitos la Declaración Política del Mercosur, Bolivia y Chile como Zona de Paz y Libre de Armas de Destrucción Masiva (1999)4, la Zona de Paz y Cooperación Sudamericana, declarada por los Presidentes de América del Sur en su Segunda Reunión celebrada en Guayaquil, Ecuador, el 27 de julio de 2002, destacada en la Resolución AG/RES. 1969 (XXXIII-O/03) de la Asamblea General de la OEA sobre Reconocimiento de la Zona de Paz y Cooperación Sudamericana5; y por la Asamblea General de la ONU en la Resolución A/RES/57/13 del 8 de enero de 2003 de la ONU; la Declaración sobre Suramérica como Zona de Paz formulada en la VI Reunión Ordinaria del Consejo de Jefes y Jefas de Estado y de Gobierno de UNASUR del 30 de noviembre de $2012^{6}$, y la Declaración Política del MERCOSUR como Zona de Paz emitida por el Parlamento del MERCOSUR (2014) 7.

Las aludidas declaraciones constituyen ejemplos que reflejan la importante labor de prevención y solución de conflictos que fue construyéndose en Latinoamérica con eje en los procesos de integración subregional, cabiendo recordar el trabajo en la materia del Consejo de Defensa Suramericano (CDS) y del Centro de Estudios Estratégicos de Defensa del Consejo de Defensa Sudamericano (CEED-CDS) con múltiples medidas de construcción de confianza, tales como la realización de ejercicios combinados, la creación y puesta en marcha de Registros de Gastos en Defensa y de Inventarios Militares en Suramérica, la construcción de lineamientos doctrinarios comunes en materia de defensa, etc.

3 Tratado Marco de Seguridad Democrática en Centroamérica, San Pedro Sula, 15 de diciembre de 1995, SICA [En línea] Fecha de Consulta, 16 de marzo de 2020, disponible en https://www.sica.int/documentos/ tratado-marco-de-seguridad-democratica-en-centroamerica_1 110795.html

4 Ushuaia, República Argentina, 24 de julio de 1999, [En línea] Fecha de consulta: 15 de marzo de 2020, disponible en https://www.oas.org/csh/spanish/c\&tdeclaracmercosurzonapaz.asp

5 Organización de las Naciones Unidas, Asamblea General, AG/RES. 1969 (XXXIII-O/03) Reconocimiento de la Zona de Paz y Cooperación Sudamericana, Nueva York, 10 de junio de 2003 [En línea] Fecha de consulta 15 de marzo de 2020, disponible en http://www.oas.org/juridico/spanish/ag03/agres_1969.htm

6 Efectuada en Lima, el 30 de noviembre de 2012. [En línea] Fecha de consulta: 15 de marzo de 2020. Disponible en:

http://sedici.unlp.edu.ar/bitstream/handle/10915/49248/Declaraci\%C3\%B3n_sobre_Suram\%C3\%A9rica_como_zona_de_paz_2_p._.pdf?sequence=3

7 Declaración Política del MERCOSUR como Zona de Paz, Montevideo, 10 de noviembre de 2014. Obtenido de Universidad Nacional de La Plata, [En línea] Fecha de consulta 16 de marzo de 2020, disponible en http://sedici.unlp.edu.ar/bitstream/handle/10915/49078/MERCOSUR_-_Declaraci\%C3\%B3n_pol\%C3\%ADtica_del_MERCOSUR_como_zona_de_paz_3_p._._politica_del_mercosur_como_zona_de_paz. pdf? sequence $=49$ \&isAllowed $=y$ 
La virtual extinción de UNASUR, como consecuencia de la decisión de Argentina, Brasil, Chile, Colombia, Paraguay y Perú de suspender su participación en UNASUR con motivo de desavenencias suscitadas con motivo de la elección del Secretario General del bloque, motivadas en la polarización ideológica suscitada en un bloque que hasta entonces contuviera a las diversas tendencias políticas existentes en el subcontinente (19 de abril de 2018) ${ }^{8}$ a lo que se sumó la decisión del presidente de Ecuador Lenin Moreno Garcés de solicitar a UNASUR la devolución del edificio en que funcionaba la secretaría general del bloque, que fuera donado al ente por su predecesor Rafael Correa ${ }^{9}$, el anuncio por parte del Gobierno de Colombia de su decisión de retirarse de UNASUR (10 de agosto del 2018) ${ }^{10}$ y el anuncio, el 15 de marzo de 2019, por parte de Lenin Moreno Garcés de su propósito de retirar a Ecuador de UNASUR ${ }^{11}$ constituyó un significativo retroceso en el camino hacia la integración.

A partir de la destitución de la presidenta brasileña Dilma Rousseff por juicio político (impeachment) y la simultánea asunción como presidente del hasta entonces vicepresidente Michel Temer (31 de agosto de 2016) a lo que cabe agregar la asunción del presidente Sebastián Piñera en Chile (2018) y, en Brasil, del capitán retirado Jair Messias Bolsonaro, quien asumió el 1 으 de enero de 2019, el panorama político latinoamericano acentuó sus cambios.

La creación de un nuevo ente de integración sudamericana en reemplazo de UNASUR, denominado Foro para el Progreso de América del Sur (PROSUR) (Santiago de Chile, 22 de marzo de 2019) que se pretendía libre de burocracia y de costos, pero que en realidad resultó libre de trascendencia, no hizo sino poner de manifiesto la apuntada crisis $^{12}$.

También cabe destacar el agravamiento de la crisis en Venezuela, iniciada con la conflictiva relación entre el gobierno electo en 1998 encabezado por el teniente coronel (R.) Hugo Chávez Frías y Estados Unidos de América, y cuyo gobierno de izquierda, de inspiración y composición mayoritariamente militar, enfrentó desde su inicio una acérrima oposición que protagonizó en 2002 una tentativa de golpe de Estado atribuida por Chávez Frías a Estados Unidos, en una sociedad profundamente dividida, y agravada tras la muerte de Chávez por los cuestionamientos dirigidos contra su sucesor Nicolás Maduro, quien perdió en las elecciones parlamentarias de 2015 la mayoría en la Asamblea Nacional, promoviendo ésta de inmediato la destitución del mandatario, mientras que éste adoptó medidas para desconocer las facultades de la Asamblea. La cotidiana confrontación y la comisión por parte de Maduro de serias violaciones a los derechos humanos fueron agravándose hasta la realización en 2018 de nuevas elecciones presidenciales en las que

8 Argentina, Brasil, Chile, Colombia, Paraguay y Perú se retiraron de la UNASUR. Infobae, Buenos Aires, 20 de abril de 2018.

9 Lenin Moreno le pedirá a la UNASUR la devolución del edificio de su sede en Quito. Infobae, Buenos Aires, 8 de julio de 2018,

10 El gobierno de Colombia anunció que se retira de la Unasur. Infobae, Buenos Aires, 10 de agosto de 2018.

11 Ecuador se retira de la Unasur y quiere la sede. Página 12. Buenos Aires. 15 de marzo de 2019.

12 HERRERA, Juan C. Prosur, el nuevo mecanismo para no integrar a Latinoamérica, The New York Times, New York, 9 de abril de 2019, [En línea] Consultado el 16 de marzo de 2020, disponible en https://www. nytimes.com/es/2019/04/09/espanol/opinion/prosur-unasur-america-latina.html 
Maduro fue reelecto, las que fueron cuestionadas por la oposición, que en su mayoría se abstuvo. La Organización de los Estados Americanos declaró ilegítimas las elecciones en cuestión, por no haber participado todos los actores, no responder el gobierno de Maduro a los estándares internacionales y carecer de las garantías necesarias ${ }^{13}$. Posteriormente, el Consejo Permanente de la entidad dispuso no reconocer como legítimo al gobierno venezolano a partir del comienzo del nuevo período presidencial de Maduro, fijado para el 10 de enero de $2019^{14}$.

Por otra parte, el presidente de la Asamblea Nacional, Juan Guaidó, se proclamó presidente encargado de Venezuela ${ }^{15}$ obteniendo el reconocimiento de la Unión Europea, numerosos países latinoamericanos y europeos, y fundamentalmente de Estados Unidos de América. Otros países latinoamericanos, como Uruguay, Bolivia, México, Nicaragua, El Salvador, Cuba, Guyana y Surinam, así como potencias extrarregionales como Rusia y China y países de otras regiones continúan reconociendo a Maduro, quien mantiene el control de la administración pública, las fuerzas armadas y la policía, así como de las restantes instituciones del Estado, excepción hecha de la Asamblea Nacional.

La conformación del denominado Grupo de Lima, conjunto de países organizado para procurar solucionar la problemática institucional de Venezuela, emitió la Declaración de Lima $^{16}$ a través de la cual sus integrantes afirmaron su vocación de contribuir a la restauración de la democracia en ese país a través de una salida pacífica y negociada; pero asumiendo como válida exclusivamente la postura de la oposición venezolana y condenando terminantemente la postura asumida por el gobierno del país, lo cual, más allá del mérito de una u otra posición, tornaba no idónea a esta instancia para una negociación real. Más adelante, el Grupo de Lima declaró ilegítimo al gobierno de Maduro surgido de las elecciones antes referidas, y reconoció al Presidente Encargado Juan Guaidó como legítimo mandatario de Venezuela.

La intimación por parte del presidente estadounidense Donald Trump a las Fuerzas Armadas venezolanas para retirar su apoyo a Maduro y de brindarlo al presidente encargado Guaidó, anunciando que sus integrantes arriesgaban su vida y su futuro de continuar haciéndolo ${ }^{17}$ fue respondida por el ministro de Defensa venezolano general Wladimir Padrino López, quien sostuvo que para cambiar el gobierno Trump tendría que "pasar sobre los cadáveres" de él y su alto mando ${ }^{18}$.

13 OEA. Asamblea General, Resolución sobre la situación en Venezuela, 5 de junio de 2018, AG/RES. 2929 (XLVIII-O/18), Secretaría General, Washington.

14 OEA. Consejo Permanente, Resolución sobre la situación en Venezuela, 9 de abril de 2019, CP40191S01, Secretaría General, Washington.

15 PONTE, Gabriela. Juan Guaidó se proclama "presidente encargado» de Venezuela, ABC Internacional, Madrid, 23 de enero de 2019 https://www.abc.es/internacional/abci-juan-guaido-proclama-presidenteinterino-venezuela-201901231844_noticia.html

16 Declaración de Lima, 8 de agosto de 2017, [En línea] Consultado el 23 de enero de 2020, disponible en https://cancilleria.gob.ar/es/actualidad/comunicados/declaracion-de-lima

17 La dura advertencia de Trump al ejército de Venezuela para que abandone su apoyo a Maduro: "Están arriesgando su vida... Lo perderán todo". BBC News Mundo, Londres, 19 de febrero de 2019, disponible en https://www.bbc.com/mundo/noticias-internacionalIbídem. 
Por su parte, Trump, preguntado por periodistas estadounidenses acerca de la posibilidad de que Estados Unidos interviniera militarmente en Venezuela, expresó que ... Todas las opciones están sobre la mesa... ${ }^{19}$.

Guaidó solicitó a Estados Unidos y a los países del Grupo de Lima una "intervención militar humanitaria" ${ }^{20}$ pero los países latinoamericanos integrantes del referido Grupo optaron por impulsar una transición por medios diplomáticos y políticos, desestimando el uso de la fuerza ${ }^{21}$.

La prudencia evidenciada por los miembros del Grupo de Lima evitó la catástrofe de una guerra en América del Sur, pero la amenaza que representa esa eventualidad permanece latente.

La virtual desaparición de UNASUR y la anunciada flexibilización del MERCOSUR por parte del presidente brasileño Jair Messias Bolsonaro ${ }^{22}$ que permitiría a sus miembros celebrar acuerdos comerciales individualmente, previsiblemente transformando la actual unión aduanera imperfecta en un área de libre comercio, permite advertir que la integración sudamericana, base de la prolongada paz de la subregión, está involucionando.

Cabe señalar que si bien la cooperación militar en el Cono Sur se ha mantenido, incluyendo tanto importantes ejercicios combinados, como, en el caso de Argentina y Chile, la Fuerza de Paz Combinada Conjunta "Cruz del Sur", o entre Argentina y Brasil la cooperación entre EMBRAER y la Fábrica de Aviones "Brigadier San Martín", en la construcción de partes por parte de la segunda para el avión de transporte KC-390 producido por la primera, prosiguiendo asimismo múltiples ejercicios combinados entre las Fuerzas Armadas de los países sudamericanos y con participación en diversos casos de países extrarregionales, lo cierto es que se ha perdido la tarea de construcción de esa cooperación en muy diversos temas, a cargo en su momento del Consejo de Defensa Sudamericano.

Es en definitiva en ese nuevo ámbito que cabe considerar la evolución reciente de las Fuerzas Armadas latinoamericanas.

19 DONALD Trump afirmó que "todas las opciones están sobre la mesa", en relación con Venezuela, Infobae, Buenos Aires, 23 de enero de 2019, [En línea] Consultado el 20 de diciembre de 2019, disponible en https:// www.infobae.com/america/venezuela/2019/01/23/donald-trump-afirmo-que-todas-las-opciones-estansobre-la-mesa-en-relacion-a-venezuela/

20 LOZANO, Daniel. Tras la violencia, Guaidó pide una intervención de la región para frenar a Maduro. La Nación, Buenos Aires, 25 de febrero de 2019.

21 Grupo de Lima no apoya intervención militar, El espectador, Bogotá, 25 de febrero de 2019, [En línea] Consultado el 15 de diciembre de 2019, disponible en https://www.elespectador.com/noticias/el-mundo/ grupo-de-lima-no-apoya-intervencion-militar-en-venezuela-articulo-841744

22 MARTIRENA, Francisco. Bolsonaro empezó a flexibilizar el Mercosur y bajará el arancel externo a bienes de capital, Bae Negocios, Buenos Aires, 24 de enero de 2019, [En línea] Consultado el 15 de febrero de 2019, disponible en https://www.baenegocios.com/economia-finanzas/Bolsonaro-empezo-a-flexibilizarel-Mercosur-y-bajara-el-arancel-externo-a-bienes-de-capital-20190123-0065.html acc. 04-05-2019. 


\section{Un marco para el análisis: las relaciones civiles-militares en América Latina}

En la introducción a la clásica obra de Huntington ${ }^{23}$ el referido autor señaló que el objetivo de la política en materia de relaciones civiles-militares es el de desarrollar un sistema de ellas en el cual se maximice la seguridad militar con el menor sacrificio posible de otros valores sociales; involucrando el logro de tal objetivo un complejo balance de poder y actitudes entre grupos civiles y militares. Si tal balance es obtenido, se acrecienta la posibilidad de encontrar las respuestas a los aspectos operacionales de la política militar. "...Las naciones que no logran ese adecuado balance, malgastan sus recursos y corren riesgos incalculables..." 24 .

Para el logro de ese balance, son fundamentales el control civil y el ejercicio idóneo por parte de la autoridad política de sus funciones de conducción de la defensa.

La expresión "control civil" en relación a las fuerzas armadas, es y ha sido siempre, como reconoce Huntington, de muy difícil definición. Señaló que:

“...Presumiblemente, el control civil tiene algo que ver con el poder relativo de grupos civiles y militares. Presumiblemente también, el control civil es alcanzado en la medida en la cual el poder de los grupos militares es reducido. Consecuentemente, el problema básico en definir el control civil es: ¿cómo puede ser minimizado el poder militar?...".

Respecto del control civil de las fuerzas armadas, ha sido destacado que ... el control civil se convierte en quién de hecho (no en teoría) establece la política de seguridad nacional y determina la asignación de recursos finitos para llenar las necesidades de seguridad... ${ }^{25}$.

También ha sido señalado que:

...El mejor indicador del estado del control civil es quién prevalece cuando las preferencias civiles y militares divergen. Si los militares prevalecen, hay un problema. Para determinar si los militares juegan un rol importante en el proceso de toma de decisiones de una sociedad, sería necesario identificar un número de asuntos que enfrentan las preferencias de los militares contra las de los civiles y ver quién prevaleció..... ${ }^{26}$

Consideramos preferible al de control civil el concepto de conducción política de la defensa, entendido como la situación en la cual las decisiones adoptadas por las autoridades electas sobre defensa y sus designados, se traducen en todos los actos

23 HUNTINGTON, Samuel. The soldier and the state. The Theory and Politics of Civil-Military Relations. The Belknap Press of Harvard University Press. Cambridge, Massachusetts and London, England, 1985, pp. 1-2.

24 Ibíd. p. 2.

25 BEN MEIR, Yehuda. Civil-Military Relations in Israel. Jaffee Center for Strategic Studies, Tel Aviv University, Columbia University Press, New York, 1999, p. 11.

$26 \mathrm{DESCH}$, Michael C. Civilian control of the military. The changing security environment. The John Hopkins University Press, Baltimore, 2001, pp. 4-5. 
realizados por los órganos estatales dedicados a la defensa, incluyendo plenamente a las Fuerzas Armadas. Ello no excluye, ciertamente -muy por el contrario, lo supone- la adecuada llegada y aprovechamiento del asesoramiento profesional militar para la toma de las decisiones fundamentales de la defensa por parte del poder político ${ }^{27}$, dado que tales decisiones deben tener por objetivo el logro de la eficiencia y eficacia en el sector $y$, en definitiva, el logro de una adecuada capacidad de defensa del país de que se trate.

Pion-Berlin ${ }^{28}$ destacó la importancia que tiene la organización de la defensa para el logro del control civil, recordando los lineamientos caracterizados por Huntington ${ }^{29}$ como "las pautas de autoridad" en relaciones civiles-militares.

Conforme destacó el autor citado en último término, tales pautas son el nivel relativo, la unidad relativa y el ámbito relativo de los grupos militares y civiles.

Señaló que el nivel relativo se refiere a la posición que el grupo respectivo ocupa en la jerarquía de la autoridad gubernamental, destacando que se ejerce control vertical sobre los militares, cuando se establece entre la máxima autoridad política y los militares otro órgano que posea autoridad sobre éstos, -habitualmente un ministerio de defensa, con conducción civil-. En segundo lugar, la unidad relativa se refiere a la extensión en que un grupo está estructuralmente unificado en su relación con otro grupo, destacando que si los militares se presentan ante la autoridad superior divididos en tres fuerzas armadas tienen menor poder que si se presentaran unidos bajo un comandante en jefe, por ejemplo. En tercer lugar, el ámbito relativo se refiere a la variedad y el tipo de autoridad y tipo de valores respecto al cual el grupo en cuestión está facultado para ejercer autoridad, señalando que, si además de la función militar tradicional, los militares están facultados para ejercer autoridad en otros aspectos, su poder será mayor ${ }^{30}$.

Consideramos este último aspecto de fundamental importancia en Latinoamérica, región caracterizada por el carácter multifuncional de sus Fuerzas Armadas.

Se ha señalado que: "...La asunción por parte de los militares latinoamericanos de un amplio orden de funciones extramilitares no es un fenómeno reciente, sino una herencia que se remonta a los orígenes de la nación misma..."31.

Además, concurrieron para explicar tal multifuncionalidad muy diversos factores, muchos de ellos señalados por Lieuwen ${ }^{32}$. Entre ellos, el caudillismo político-militar que sobrevino a la conquista de la independencia, en los Estados latinoamericanos, excepción

27 UGARTE, José Manuel. Una visión desde Latinoamérica de la organización de la defensa y relaciones civiles-militares. En: PION-BERLIN, David y Ugarte, José Manuel. Organización de la defensa y control civil de las Fuerzas Armadas en América Latina, Buenos Aires, Jorge Baudino Editores, 2013, p. 55.

28 PION-BERLIN, David (2013). La Organización de la Defensa y relaciones civiles-militares en América Latina.

En: Pion-BERLIN, David y Ugarte, José Manuel. Loc. Cit. pp. 21-52.

29 HUNTINGTON, Samuel. Op. Cit. p. 80.

30 Ibíd. pp. 87-88.

31 LIEWEN, Edwin. Armas y política en América Latina, Sur, Buenos Aires, 1960, p. 25.

32 Ibíd. pp. 80-87. 
hecha de Chile y Brasil; los cambios sociales y la depresión económica, que llevaron militares al gobierno de diversos países de la región, etc.

Tales características se acentuaron notablemente durante la Guerra Fría.

En dicha época los roles de las Fuerzas Armadas latinoamericanas comprendieron desde el ejercicio del gobierno en la mayoría de los países, hasta el control de la seguridad interna y de la actividad de inteligencia, la realización de actividades empresarias, así como la defensa civil, entre otros aspectos.

Creemos que para lograr una conducción política de la defensa, no basta con lograr la minimización del poder militar aludida por Huntington ${ }^{33}$.

Resulta de fundamental importancia que la ya señalada conducción política de la defensa sea ejercida con idoneidad y lucidez, considerando debidamente el asesoramiento militar y la idoneidad y experiencia de éstos.

En la clásica formulación de Huntington encontramos dos formas fundamentales de control civil: la primera, el control civil subjetivo, maximizando el poder de los civiles, o, en la práctica, de determinados civiles que ejercen poder sobre los militares ${ }^{34}$.

En cambio, el control civil objetivo se logra, conforme al referido autor, maximizando el profesionalismo militar, distribuyéndose el poder político entre grupos militares y civiles procurándose el surgimiento de actitudes y comportamientos profesionales por parte del cuerpo de oficiales, transformándolos en un instrumento del Estado, políticamente estéril y neutral, siendo el núcleo de la competencia militar la administración de la violencia; en esencia, combatir exitosamente ${ }^{35}$.

Finer ${ }^{36}$ cuestionó que el logro del profesionalismo militar fuera la base del control civil, señalando que cuerpos de oficiales altamente profesionalizados, como el alemán y el japonés, habían intervenido en política, y que no era útil replicar que no serían "plenamente profesionales" afirmando que, para Huntington, todo dependería de una especial definición de "profesionalismo". Sostuvo que si los militares se abstenían de intervenir era en virtud de un principio explícito, el "principio de supremacía civil".

Sin dejar de reconocer la lucidez de la crítica de Finer, creemos que éste omite un aspecto fundamental del control civil objetivo de Huntington: la adecuada distribución del poder político entre grupos militares y civiles, que precisamente no se produjo en los dos ejemplos citados por Finer -que están precisamente entre los ejemplos brindados por Huntington ${ }^{37}$ como inadecuados por no realizar tal distribución, con acceso inmediato a la máxima autoridad estatal, maximización del poder militar dentro del Estado, entre otros

33 HUNTINGTON, Samuel. Op. Cit. p. 84.

34 bíd. pp. 80-84.

35 Ibíd. pp. 83-85.

36 FINER, Samuel E. The man on horseback. The Role of the Military in Politics. Transaction Publishers New Brunswick and London, Fourth printing, 2006, pp. 24-30.

37 HUNTINGTON, Samuel. Op. Cit. pp. 98-142. 
aspectos- ni tampoco en Latinoamérica.

Pero más elusiva se muestra la búsqueda de los factores que producen el reconocimiento por parte de los militares del "principio de supremacía civil" de Finer.

Finer ${ }^{38}$ ensayó diversas explicaciones, vinculando tipos de intervención militar con el nivel de cultura de la sociedad distinguiendo varios niveles de intervención militar, y relacionándolos con los niveles de cultura política, sosteniendo que los niveles de intervención política de los militares variaban conforme al nivel de cultura política de la sociedad de que se trataba.

Destacó las condiciones que proporcionaban estabilidad política: existencia y fuerza de las organizaciones que con su accionar integraban los diversos grupos sociales. Afirmó que el desarrollo de estas asociaciones requeriría la concurrencia de precondiciones materiales: un alto grado de intercambio comercial y actividad industrial, y un alto nivel de ingreso nacional ${ }^{39}$.

Contrasta con tales nociones el fenómeno de la democratización de América Latina, que comprendió a países considerados como de media o baja cultura política, y que ciertamente estaban y están lejos de alcanzar las precondiciones materiales antes descriptas.

En uno de los análisis más interesantes realizados en Estados sobre la evolución de las relaciones civiles-militares en Latinoamérica, John Samuel Fitch ${ }^{40}$ advirtió que "... La llegada de la guerra fría en América Latina marcó el comienzo de otra variación..." señalando que los cambios en la doctrina militar y el contexto político se combinaron para dar forma a un nuevo concepto de profesionalismo militar.

Señaló dicho autor que en la Guerra Fría, con límites no claros entre paz y guerra, la misión militar no constituyó simplemente en derrotar militarmente al enemigo, sino en proteger la capacidad del Estado de alcanzar sus objetivos nacionales, no limitados solamente a la integridad territorial. Destacó que en consecuencia la misión militar fue definida en términos de seguridad nacional, más que en la tradicional defensa nacional, dependiendo la primera del poder nacional que comprendía los factores económico, psicosocial, internacional y militar.

Sostuvo Fitch que el efecto de esta redefinición de la misión militar fue el de borrar muchos de los límites entre las esferas de competencia militares y civiles sobre las cuales reposaba el argumento anti intervencionista del profesionalismo militar clásico.

Una de las consecuencias de dichas doctrinas fueron la asunción por parte de las Fuerzas Armadas de roles de suma amplitud, así como la subordinación de las fuerzas de seguridad y las policías a las Fuerzas Armadas, el monopolio militar de la actividad

38 FINER, Samuel E. Op. Cit. pp. 86-109.

39 Ibíd. pp. 226-228.

40 FITCH, John Samuel. The Armed Forces and Democracy in Latin America, The John Hopkins University Press, Baltimore \& London, 1998, p. 12. 
de inteligencia, y la realización de golpes del Estado en los países latinoamericanos por parte de las Fuerzas Armadas, que asumieron el poder con apoyo estadounidense por entenderse que de ese modo se adquiría mayor eficacia en la lucha contra el comunismo.

Así, en el marco de la Guerra Fría, los roles de las Fuerzas Armadas latinoamericanas comprendieron desde el ejercicio del gobierno, hasta el control de la seguridad interna y de la actividad de inteligencia en los países señalados, la realización de actividades empresarias vinculadas y no vinculadas con la defensa nacional, así como actividades de defensa civil con una concepción sumamente ampliada, como también el desempeño de muy diversas actividades de carácter civil. Todos los países de la región, excepción hecha de México, Colombia y Venezuela, donde las Fuerzas Armadas, de todos modos, incrementaron su influencia, y Costa Rica, por carecer de Fuerzas Armadas, pasaron durante la Guerra Fría en diversos momentos a tener gobierno militar.

La redemocratización de Latinoamérica, que comenzara a fines de la Guerra Fría y se acelerara con la finalización de dicho conflicto, no disminuyó en grado significativo la amplitud de los roles de las Fuerzas Armadas latinoamericanas, con la obvia excepción del ejercicio del gobierno. Ello, excepción hecha de Argentina, -salvo situaciones de que se dará cuenta- y de Chile -con algunas novedades recientes-, y salvo las funciones de policía naval y aérea ejercidas respectivamente por la Armada y la Fuerza Aérea de dicho país.

Con las excepciones apuntadas, las funciones de las Fuerzas Armadas latinoamericanas incluyen la intervención en la seguridad interior en diversos grados según los países, la dirección (en la casi totalidad de los países) de la actividad de inteligencia incluyendo la actividad de inteligencia civil, la participación en el desarrollo del país, que en diversos casos incluye la realización de actividades empresarias, la protección civil ante desastres naturales o antrópicos y la realización de tareas de apoyo a la comunidad a requerimiento del poder político o en algunos casos en forma autónoma.

Respecto de las doctrinas militares que caracterizaron a las Fuerzas Armadas latinoamericanas durante la Guerra Fría, cabe recordar dos vertientes fundamentales: la doctrina de la seguridad nacional, y la doctrina de contrainsurgencia.

La primera estuvo basada en la utilización del concepto de seguridad nacional, asignándole una significativa amplitud, equivalente a la de los conceptos tradicionales de defensa nacional y de seguridad interior, así como a la mayor parte de la política exterior e interior del país en el que se aplicaba.

Por otro lado, al definir el concepto de defensa nacional como el conjunto de medidas destinadas al logro de la seguridad nacional, se asignaba idéntica amplitud a ambos conceptos, pasando el concepto clásico de defensa nacional a abarcar también la seguridad interior y los aspectos fundamentales de la política exterior e interior del país, incluyendo el desarrollo, brindando bases para la intervención militar en los más diversos ámbitos.

Con relación a las doctrinas de contrainsurgencia, tuvieron origen en la lucha de la Francia colonial contra los movimientos independentistas de Indochina y Argelia, 
preconizando la guerra contrarrevolucionaria, incluyendo tácticas caracterizadas por la asignación a las Fuerzas Armadas del rol fundamental en la lucha, configuradas a tal fin con un despliegue cubriendo el territorio incluyendo los centros poblados, subordinando a aquéllas a las policías; la creación de un movimiento de apoyo entre la población que incluía la organización en ésta de redes de informantes, observadores, patrullas y otras formas de apoyo, un control territorial a través de la división en cuadrículas, el empleo de los organismos de inteligencia militares, y el uso sistemático de la tortura como medio de obtención de información, entre otros aspectos.

En Estados Unidos, la contrainsurgencia fue plenamente adoptada como instrumento destinado a aquellos países que se consideraba amenazados por el comunismo ${ }^{41}$, constituyendo un componente fundamental del adiestramiento suministrado por Estados Unidos a las Fuerzas Armadas latinoamericanas durante la Guerra Fría.

Busso ${ }^{42}$, ha observado que habiendo sido la presencia de gobiernos autoritarios una característica de la América Latina de los 70, tales gobiernos reunían rasgos comunes que los diferenciaban de los anteriormente existentes en la región.

En ellos, las fuerzas armadas pasaron a desempeñar un papel preponderante, comprometiéndose en la conducción del país a través de su institucionalidad jerárquica, y con doctrinas y modos de acción similares.

Así como la casi totalidad de la región cayó en las décadas de los 60 y 70 bajo control militar, con la misma simultaneidad se produjo la redemocratización de la región, pero produciéndose en muy diversos grados.

Cabe también coincidir con Busso ${ }^{43}$ en el carácter significativo del rol estadounidense en la redemocratización de América Latina.

La redemocratización de Latinoamérica no disminuyó en grado significativo los roles de las Fuerzas Armadas latinoamericanas. Excepción hecha de Argentina y de Chile -salvo aspectos marginales- las funciones de las Fuerzas Armadas latinoamericanas incluyen la intervención en la seguridad interior en diversos grados según los países, el control de la actividad de inteligencia incluyendo en la casi totalidad de los casos la actividad de inteligencia civil, la participación en el desarrollo del país, y la realización de tareas de apoyo a la comunidad.

En la generalidad de los casos, la amplitud de la misión militar es una característica de la gran mayoría de las Fuerzas Armadas latinoamericanas. Particularmente cuando tal

41 MAECHLING, Charles. Contrainsurgencia: La primera prueba de fuego. En: KLARE, Michael y KORNBLUH, Peter. Contrainsurgencia, proinsurgencia y antiterrorismo en los 80 . El arte de la guerra de baja intensidad, Grijalbo, Ciudad de México, 1990, p. 40.

42 BUSSO, Anabella (1991). Estados Unidos y la redemocratización latinoamericana: los condicionantes externos, Revista Estudios Internacionales, Volumen 24 Número 94 Universidad de Chile, Santiago de Chile, [En línea] Consultado el 25 de mayo de 2019, disponible en https://revistaei.uchile.cl/index.php/ REI/article/download/15460/15913/

43 Ibíd. p. 265. 
misión incluye el control de la seguridad interior y de la actividad de inteligencia, aparece como imprescindible la necesidad de contar con la cooperación de tales fuerzas para asegurar el orden público y la gobernabilidad, circunstancia que unida a la tradición de intervención en la política de muchas de ellas, torna extremadamente difícil el logro de la conducción política de la defensa.

En las restantes "pautas de autoridad" señaladas por Huntington y por Pion-Berlin, cabe destacar que respecto del nivel relativo en Latinoamérica existen casos como los de México -que carece de Ministerio de Defensa, contando con dos secretarías militares- y de Guatemala, en el que el ministro de Defensa debe ser estatutariamente militar. En otros supuestos, aun cuando no constituya una exigencia estatutaria, tiene actualmente tal carácter en Brasil, Cuba, Ecuador, El Salvador, Honduras, Nicaragua, Paraguay, Perú, República Dominicana y Venezuela. Cabe recordar que en casos como Brasil, Ecuador y Perú, ello ha sucedido en los últimos años.

La circunstancia de ser militar el titular del Ministerio de Defensa, ya sea un militar en actividad o que, aun siendo retirado, posea una fuerte vinculación y sentido de pertenencia con la institución de origen, circunstancia común en Latinoamérica, determina que resulta muy difícil que tal ministerio pueda cumplir adecuadamente la función propia del control civil de constituir el órgano a través del cual las directivas, orientaciones y políticas del presidente se materializan acabadamente en las acciones adoptadas por el Ministerio y por las Fuerzas Armadas, en todos los aspectos vinculados a la defensa, y a través del cual se brinde al presidente el adecuado asesoramiento civil y militar en temas de defensa. En la práctica, lo que sucede es que las Fuerzas Armadas, a través del ministro militar, llegan directamente al presidente, pasando a tener dicho origen toda la información sobre tales aspectos que llega a aquél.

En materia de información e inteligencia, preciso es señalar que actualmente, en Latinoamérica, existen solo dos casos -Argentina y Ecuador- en los que el titular del principal organismo civil de inteligencia tiene carácter civil. Tales organismos, en los restantes casos, tienen conducción militar.

Cabe señalar que además de la circunstancia enunciada, pocos ministerios de Defensa latinoamericanos cuentan con las facultades constitucionales y legales necesarias para cumplir con las funciones antes enunciadas.

En efecto, como hemos señalado en otra oportunidad ${ }^{44}$ encontramos ministerios de Defensa cuyas funciones son exclusivamente administrativas, como son los casos de Bolivia y Venezuela, que confían las funciones técnico-militares y operativas a un Comandante en Jefe, quien a tal efecto depende directamente del presidente, o bien Nicaragua, donde el ministro de Defensa tiene por función la de dirigir la elaboración de las políticas y estrategias de la defensa y de apoyar al presidente en la obtención de las condiciones, recursos y mecanismos para que el Ejército cumpla su misión, así como en la preparación del presupuesto, entre otras tareas, sin que se establezca subordinación del Ejército respecto del ministerio en asuntos administrativos, operativos o técnico-militares.

44 UGARTE, José Manuel. Op. Cit. pp. 66-68 y 70-72. 
Analizaremos a continuación diversos casos nacionales útiles para arribar a conclusiones.

\section{Análisis de casos nacionales}

\subsection{Argentina}

Argentina alcanzó un grado significativo de control civil de sus Fuerzas Armadas, ayudada por la virtual retirada del gobierno militar, producida como consecuencia de la derrota experimentada en el Conflicto Malvinas (1982).

La Ley № 23.554 de Defensa Nacional ${ }^{45}$ concluyó con la amplitud ilimitada de los conceptos de seguridad nacional y de defensa nacional que caracterizaran a la Ley № 16.970, limitando el ámbito de la defensa a la preparación durante la paz, y la respuesta en caso de guerra, ante agresiones externas de carácter militar.

La Ley № $24.059^{46}$ de Seguridad Interior limitó el rol de las Fuerzas Armadas en seguridad Interior al apoyo a las operaciones de Seguridad Interior "... con sus servicios de arsenales, intendencia, sanidad, veterinaria, construcciones y transporte, así como de elementos de ingenieros y comunicaciones..." ${ }^{47}$ (artículo 27) permitiendo el empleo de los elementos de combate solo en aquellos casos excepcionales en los cuales el sistema de seguridad interior resultare insuficiente para alcanzar o mantener la situación de seguridad interior, en situaciones de extrema gravedad (artículos 31 y 32 ).

A su vez, la Ley № $24.948^{48}$ de Reestructuración de las Fuerzas Armadas, agregó dos nuevas misiones: las operaciones en el marco de las Naciones Unidas -Operaciones de paz- y las operaciones en apoyo de la comunidad o de países amigos.

Por otra parte, el Decreto № 727/200649 reglamentario de la Ley № 23.554, precisó, respecto de la misión de las Fuerzas Armadas, que dichas Fuerzas serían empleadas exclusivamente ante agresiones de origen externo perpetradas por fuerzas armadas pertenecientes a otro/s Estados.

Con relación a la estructura y organización de la defensa establecidas en la Ley № 23.554 de Defensa Nacional, cabe señalar que en materia de facultades del Presidente de la Nación, el artículo 10 le asignó la dirección de la Defensa Nacional y la conducción de las Fuerzas Armadas.

Un aspecto de importancia es el relativo a las amplias facultades del Ministerio de Defensa, del que dependen por delegación del Presidente de la Nación las Fuerzas Armadas (artículo 23) así como el Estado Mayor Conjunto (artículo 16). Dicho ministerio,

45 Ley № 23.554 DE DEFENSA NACIONAL. Boletín Oficial, Buenos Aires, 5 de mayo de 1988.

46 Ley № 24.059 DE SEGURIDAD INTERIOR. Boletín Oficial, Buenos Aires, 17 de enero de 1992.

47 Ibíd.

48 Ley № 24.498 DE REESTRUCTURACIÓN DE LAS FUERZAS ARMADAS. Boletín Oficial, Buenos Aires, 8 de abril de 1998.

49 Decreto № 727/2006, Boletín Oficial, Buenos Aires, 13 de junio de 2006. 
desde la restauración de la democracia, ha estado bajo conducción civil.

Por otra parte, el Estado Mayor Conjunto ejerce en exclusividad -bajo control del Presidente de la Nación y del Ministro de Defensa- todas las funciones propias del accionar conjunto, incluyendo el planeamiento y el adiestramiento conjuntos.

Cabe señalar que durante el período de gobierno del presidente ingeniero Mauricio Macri (10 de diciembre de 2015) fue dictado el Decreto № 683/2018 ${ }^{50}$, que modificó el Decreto № 727/2006 ampliando el ámbito de la defensa nacional a las agresiones externas de cualquier tipo, contraviniendo lo establecido por la ley reglamentada, de la que surge que tales agresiones deben ser de carácter militar.

Por otra parte, el presidente Macri emitió una nueva "Directiva de Defensa Nacional", por Decreto № 703/2018 ${ }^{51}$, en la que se afirmó que la seguridad de los Estados latinoamericanos estaría afectada por el narcotráfico, la piratería, la trata de personas y el contrabando, cuya atención prioritaria correspondía a los organismos de seguridad, inteligencia e inteligencia criminal, señalando que las Fuerzas Armadas contaban con capacidades que podían ser empleadas en apoyo a la lucha contra estas problemáticas.

Cabe mencionar la realización del Operativo "Integración Norte", en la frontera norte, dispuesto por Resolución № $860 / 2018^{52}$ del Ministerio de Defensa, consistente en tareas denominadas de apoyo logístico a las Fuerzas de Seguridad -vedado por la Lay № 24.059 de Seguridad Interior, en tanto comprendió a elementos de combateadiestramiento operacional y apoyo a la comunidad. Este operativo ha sido reiterado en 2019, (Ministerio de Defensa 2019, y Estado Mayor Conjunto, 2019).

En otro orden de ideas, cabe señalar que una combinación de factores tales como reducciones en el presupuesto de defensa, sin realizar la reestructuración que permitiera a las Fuerzas Armadas adaptarse a créditos presupuestarios más reducidos; excesivo número de personal en los grados más altos, con la consecuencia de un mayor gasto en personal; escasez de fondos, para mantenimiento del material y adiestramiento del personal; y virtual inexistencia de reequipamiento, con la consecuencia de la creciente obsolescencia del material disponible, han llevado a las Fuerzas Armadas argentinas a una situación lindante con la imposibilidad de operar ${ }^{53}$.

Las circunstancias expuestas se reflejaron en un gasto en personal -incluyendo pensiones- superior al $80 \%$, un gasto insuficiente en funcionamiento (mantenimiento y adiestramiento, fundamentalmente) entre el $13 \%$ y el $17 \%$, que erosionó el mantenimiento del material y el entrenamiento del personal, y entre un $1 \%$ y $5 \%$ en inversiones, que

50 Decreto № 683/2018, Boletín Oficial, Buenos Aires, 24 de julio de 2018.

51 Decreto № 703/2018, Boletín Oficial, Buenos Aires, 31 de julio de 2018.

52 Resolución № 860/2018 del Ministerio de Defensa. No publicada en el Boletín Oficial. Texto [En línea] Consultado el 15 de diciembre de 2019. Disponible en https://liganaval.org.ar/Operativo-IntegraciónNorte.pdf

53 UGARTE, José Manuel. Defensa indefensa, o apariencia de defensa: la política de defensa argentina; Perspectivas Revista de Ciencias Sociales (PRCS) No. 7 Enero-Junio 2019, [En línea] Consultado el 20 de septiembre de 2019. Disponible en http://hdl.handle.net/2133/15383. 
trajo consigo la virtual imposibilidad de reequipar a las Fuerzas Armadas. Ello, para un presupuesto de defensa que fue reduciéndose del 2,4\% del PBI en 1985, al 1,5\% en 1990 y $1,1 \%$ del PBI en 1997, oscilando a partir del 2004 entre el $0,8 \%$ y el $1 \%$ del PBI.

Tal situación se ha mantenido por espacio de 28 años, agravándose durante los últimos años. Así, las proporciones fueron para 2015, personal del 85,4\%, en funcionamiento del $16 \%$, e inversiones por 3,5\%. Para $2016,82 \%, 13 \%$, y 3,9\%. Para 2017 , de $81,80 \%, 14,3 \%$ y $3,8 \%$. Para 2018, 86,37\%; 9\%; 3,24\%. Para 2019, $87 \%, 8,5 \%$ y $1,8 \%$. (Leyes de Presupuesto para 2015, 2016, 2017, 2018 y 2019, jurisdicción Defensa más pasividad militar).

Las consecuencias de las circunstancias descriptas son: medios materiales con tres, cuatro o cinco décadas de antigüedad, sin modernizaciones o con modernizaciones interrumpidas por falta de presupuesto, en mal estado de mantenimiento o simplemente inoperables.

Las apreciaciones indicadas no son meramente subjetivas. El clásico The Military Balance 2017 señalaba sobre Argentina que “...después de un largo período de relativa negligencia y baja inversión, hay un requerimiento para reemplazar un gran número de plataformas antiguas, inoperables y retiradas..." ${ }^{54}$.

Se debe señalar que concluido el 10 de diciembre de 2019 el período de Macri, asumió la presidencia el abogado Alberto Fernández, de signo político diverso a su predecesor, designando como ministro de Defensa al ingeniero Agustín Rossi, que se desempeñara en idéntico cargo durante el gobierno encabezado por la abogada Cristina Fernández. Con anterioridad al cambio de gobierno y siendo diputado nacional, Rossi presentó un proyecto de ley de creación de un Fondo Nacional de la Defensa (FONDEF) a fin de financiar el reequipamiento de las Fuerzas Armadas formado por un porcentaje inicial del $0,35 \%$ del total de los ingresos corrientes previstos en el presupuesto, incrementado progresivamente hasta llegar al 0,8\% para el año 2023, manteniéndose en dicho porcentaje. El proyecto alcanzó media sanción en la Cámara de Diputados, no habiendo sido remitido por el órgano ejecutivo para su tratamiento en sesiones extraordinarias, aguardándose con expectativa su tratamiento en sesiones ordinarias.

\subsection{Brasil}

En Brasil, una paulatina apertura y logros económicos determinaron que las Fuerzas Armadas entregaran el poder en una posición de fuerza. Tal posición incluyó una misión militar amplia -reflejada en la Constitución de 1988-influencia en la seguridad interior, la persistencia de los ministerios militares, dependencia directa del Presidente de la Nación, y control de la actividad de inteligencia civil y militar.

De la Constitución brasileña de $1988^{55}$ (artículo 142) surgen las características

54 International Institute for Strategic Studies, The Military Balance 2017, London, 2017, p. 423.

55 Constituiçao da República Federativa do Brasil de 1988, Presidência da República, Casa Civil, Subchefia de Assuntos Jurídicos [En línea] Consultado el 10 de diciembre de 2019. Disponible en http://www.planalto. gov.br/ccivil_03/constituicao/constituicao.htm 
multifuncionales de las fuerzas armadas brasileñas. Además de la defensa, dichas fuerzas están destinadas a garantizar a los poderes constitucionales y, por iniciativa de cualquiera de ellos, la ley y el orden.

También surge de la referida Constitución que las Policías Militares y los Cuerpos de Bomberos Militares estaduales, a cargo de la función de policía de seguridad en los estados, aunque subordinadas a los gobernadores, son fuerzas auxiliares y reserva del Ejército (artículo 144 apartado $6^{\circ}$ ), quien mantiene un rol en materia de doctrina, equipamiento y disciplina de las instituciones nombradas a través de la Inspectoría General de las Policías Militares y de los Cuerpos de Bomberos Militares, que depende del Comando del Ejército (Decreto-Ley № 667/196956).

El Ministerio de Defensa es de creación relativamente reciente en Brasil; fue formalmente establecido por la Ley Complementaria $\mathrm{N}^{\circ} 97^{57}$ sustituyendo a los antiguos Ministerios Militares.

La referida ley y sus modificatorias Leyes Complementarias $\mathrm{N}^{\circ} 117^{58}$ y $\mathrm{N}^{\circ} 136^{59}$ mantuvieron e incluso incrementaron el ya señalado carácter multifuncional de las fuerzas armadas brasileñas.

En efecto, la referida ley, tras reiterar textualmente el ya citado artículo 142 primer párrafo de la Constitución, estableció como atribución subsidiaria de las Fuerzas Armadas: cooperar con el desarrollo nacional y la defensa civil, incluyendo la participación en campañas institucionales de utilidad pública y de interés social.

En materia de seguridad pública, el artículo 16 facultó a las Fuerzas Armadas brasileñas a actuar en la franja de frontera terrestre, en el mar y en las aguas interiores, contra delitos transfronterizos y ambientales.

Cabe destacar en lo relativo a la actividad de inteligencia, que además del obvio control sobre la inteligencia militar, las Fuerzas Armadas controlan, a través de un órgano que se encuentra estatutariamente bajo la conducción de un oficial militar en actividad, el Gabinete de Seguridad Institucional (GSI), la inteligencia civil representada por la Agencia Brasileña de Inteligencia (ABIN), dependiente del GSI, (artículo 11, punto V, Ley $\mathrm{N}^{\circ}$ 13.502) que además es la agencia central del Sistema de Inteligencia Brasileño (SISBIN) y ejercen además la coordinación del aludido SISBIN (art. $3^{\circ}$, (Ley N 9.883/199960 y Decreto $4.376 / 2002^{61}$ (artículo 4을 apartado II y modificatorios).

Conforme establece actualmente la Sección VI, artículos 10 y 11 de la Ley $N^{\circ}$ $13.844^{62}$, el GSI, que depende directamente del Presidente de la República, tiene entre sus

56 Decreto Lei 667 de 1967, Diário Oficial da União, Brasília, 3 de julio de 1969.

57 Lei Complementar № 97, Diário Oficial da União, Brasília, 10 de junio de 1999.

58 Lei Complementar № 117, Diário Oficial da União, Brasília, 3 de septiembre de 2004.

59 Lei Complementar № 136, Diário Oficial da União, Brasília, 26 de agosto de 2010.

60 Lei № 9883 de 1999, Diário Oficial da União, Brasília, 8 de diciembre de 1999.

61 Decreto № 4376/2002, Diário Oficial da União, Brasília, 16 de septiembre de 2002.

62 Lei № 13.844, Diário Oficial da União, Brasília, 18 de junio de 2019. 
facultades (artículo 10) las de asistir directa e inmediatamente al Presidente de la República en el desempeño de sus atribuciones, especialmente en cuanto a asuntos militares y de seguridad y coordinar las actividades de inteligencia federal. EI GSI tiene también a su cargo la protección de la seguridad del Presidente, Vicepresidente, principales órganos de la Presidencia de la República, y de los palacios presidenciales. Su titular, el Ministro-Jefe del GSI, tiene además a su cargo la Secretaría Ejecutiva del Consejo de Defensa Nacional y preside la Cámara de Relaciones Exteriores y Defensa Nacional del Consejo de Gobierno.

Amerita señalar que el GSI fue originariamente creado bajo la presidencia de Fernando Henrique Cardoso, casi simultáneamente con el Ministerio de Defensa, lo que permite conjeturar que los militares brasileños compensaron la pérdida de poder que experimentaban con el fin de los Ministerios Militares, con un órgano que les permitía una instancia directa con el presidente en materia de defensa y seguridad, y al propio tiempo les aseguraba el control de la actividad de inteligencia. Además, como se verá, se aseguraron el control de los órganos de formulación de la política de defensa dentro del Ministerio de Defensa.

Cabe señalar que la presidenta Dilma Rousseff (2011-agosto de 2016) suprimió el GSI (Medida Provisoria № 696/2015 ${ }^{63}$ ratificada por Ley № $13.266^{64}$ ), estableciendo que la coordinación de la actividad de inteligencia federal, y la dependencia de la Agencia Brasileña de Inteligencia, eran asignadas a la Secretaría de Gobierno.

Habiendo cesado Rousseff en su cargo provisoriamente el 12 de mayo de 2016 por vía de impeachment para afrontar su juzgamiento por el Senado, por el que resultaría destituida el 31 de agosto del mismo año, asumió interinamente el mismo día el vicepresidente Michel Temer, como presidente interino, dictando ese mismo día 12 de mayo de 2016 la Medida Provisoria № 726 de 2016 ${ }^{65}$, restableciendo el GSI.

Entre las facultades del aludido GSI -que han crecido significativamente desde su restablecimiento en 2016- se cuentan además de las ya referidas (artículo 10, Ley № 13.844) coordinar las actividades de seguridad de información y de las comunicaciones en el ámbito de la administración pública federal, incluyendo la seguridad cibernética, la protección de datos, la protección del Plan Nuclear Brasileño, cuestiones referentes al sector espacial brasileño, así como asuntos relativos al terrorismo, su prevención y neutralización, y asuntos relativos a infraestructura crítica.

Cabe señalar que el mismo año 2016 se dictó el Decreto № $8903^{66}$ a través del cual se creó el Programa de Protección Integrada de Fronteras (PPIF) destinado a coordinar la prevención, control, fiscalización y prevención de los delitos transfronterizos, teniendo a su cargo también el GSI la Secretaría Ejecutiva del Comité Ejecutivo del PPIF, que entre otros aspectos prevé la actuación integrada y coordinada de los órganos de seguridad pública, de inteligencia, aduaneros, impositivos y de las Fuerzas Armadas, contra los aludidos delitos transfronterizos.

63 Medida Provisória № 696/2015, Diário Oficial da União, Brasília, 6 de octubre de 2015.

64 Lei № 13.266, Diário Oficial da União, Brasília, 6 de abril de 2016.

65 Medida Provisória № 726 de 2016, Diário Oficial da União, Brasília, 19 de mayo de 2016.

66 Decreto № 8903/2016, Diário Oficial da União, Brasília, 17 de noviembre de 2016. 
La Ley № $13.491^{67}$ estableció la competencia de la Justicia Militar en aquellos delitos dolosos contra la vida y cometidos por militares de las Fuerzas Armadas contra civiles, si fueran practicados en el contexto de atribuciones establecidas por el Presidente de la República o por el ministro de Defensa, o de una operación de paz, de garantía de la ley y del orden o de una atribución subsidiaria de las Fuerzas Armadas, entre otras hipótesis.

En relación a otros aspectos de la organización de la defensa en Brasil, cabe destacar que conforme a la Ley Complementaria № 97, las Fuerzas Armadas dependen y están subordinadas al ministro de Defensa, de quien depende asimismo el Estado Mayor Conjunto de las Fuerzas Armadas órgano militar de asesoramiento del ministro en aspectos que incluyen la política y estrategia de defensa, la inteligencia de defensa, y el planeamiento de empleo conjunto de las Fuerzas Armadas, la logística conjunta, y la articulación y equipamiento y de coordinación de la actuación de aquéllas en aspectos comunes a ella, como la protección civil (Decreto № 9570/201868, artículo 10).

Los Comandantes de Fuerza, (artículo $4^{\circ}$ de la Ley Complementaria), tienen a su cargo, entre otras facultades, la dirección y la gestión de la respectiva Fuerza.

Cabe señalar que las funciones de formulación de la política y estrategia de defensa, la inteligencia estratégica y operativa de defensa, la movilización, los aspectos de ciencia y tecnología de la defensa, los aspectos presupuestarios y, en definitiva, los aspectos sustantivos de la labor del Ministerio de Defensa, están en el referido ministerio confiados a un órgano militar: el Estado Mayor Conjunto de las Fuerzas Armadas. En definitiva, el asesoramiento de que dispone el Ministro en materia de política, estrategia e inteligencia de defensa, es exclusivamente militar, a partir del Decreto № 7.364/2010 ${ }^{69}$, continuando con

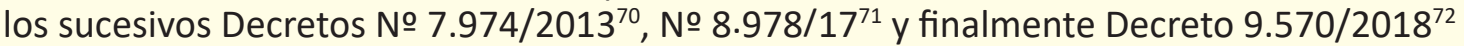
actualmente vigente, aprobatorio de la actual estructura del Ministerio.

Hay no obstante novedades. Hoy, el ministro de Defensa es general de ejército en actividad, habiendo estado ese cargo ininterrumpidamente en manos civiles hasta la designación de un militar durante el gobierno encabezado por Michel Temer. Todos los miembros del gabinete del actual ministro son militares, así como el Secretario General del Ministerio, el Secretario de Personal, Salud, Enseñanza y Deporte, y el Secretario de Productos de Defensa, entre otros muchos funcionarios del ministerio.

En definitiva, el Presidente de Brasil -hoy un militar retirado- y su vicepresidente también militar retirado, general Antônio Hamilton Martins Mourão, reciben asesoramiento en materia de defensa del Ministerio de Defensa, exclusivamente de personal militar. Son militares los ministros Fernando Azevedo Silva, ministro de Defensa, además del MinistroJefe del GSI, y otros cinco ministros.

67 Lei № 13491, Diário Oficial da União, Brasília, 16 de octubre de 2017.

68 Decreto № 9.570/2018, Diário Oficial da União, Brasília, 21 de noviembre de 2018.

69 Decreto № 7.364/2010 Diário Oficial da União, Brasília, 24 de noviembre de 2010.

70 Decretos № 7974/2013 Diário Oficial da União, Brasília, 2 de abril de 2013.

71 Decreto № 8.978/2017 Diário Oficial da União, Brasília, 2 de febrero de 2017.

72 Decreto № 9.570/2018. Loc. Cit. 
En suma, a partir del mismo día en que concluyó el desempeño de la presidenta Rousseff y asumió interinamente el presidente Temer, y cuando se produjo el restablecimiento del GSI, fue establecida la jurisdicción de la justicia militar sobre los delitos cometidos por los militares en ejercicio de funciones de seguridad interior, fue incrementado el ejercicio de tales funciones, y fueron designados al frente del Ministerio de Defensa a militares en actividad. Si anteriormente no podía hablarse de un grado significativo de control civil sobre las Fuerzas Armadas, hoy tal control prácticamente no existe.

\subsection{Chile}

En Chile, a semejanza de Brasil, una transición pactada dejó importantes resortes de poder en manos militares.

No obstante, a diferencia de aquél, en un largo y complejo proceso Chile logró superar tal circunstancia a través de reformas constitucionales -especialmente la de 2005- y de reformas legales, destacándose especialmente la Ley № $20.424^{73}$ Estatuto Orgánico del Ministerio de Defensa Nacional, así como la Ley $19.974^{74}$ Sobre el Sistema de Inteligencia del Estado y Crea la Agencia Nacional de Inteligencia.

Cabe señalar que con anterioridad a la sanción de la Ley № 20.424, el Ministerio de Defensa chileno constituía un órgano con funciones limitadas y una estructura insuficiente para la formulación de políticas sustantivas en materia de defensa.

En las materias relativas a la política de Defensa, tenían competencia diversos Consejos, con predominante o significativa presencia de las Fuerzas Armadas.

En lo relativo a la estructura del Ministerio de Defensa, con anterioridad a la sanción de la Ley № $20.424^{75}$, merece señalarse que comprendía órganos con facultades fundamentalmente administrativas, debiendo compartir facultades en los aspectos fundamentales de la política de defensa y en los aspectos operacionales con las Fuerzas Armadas, a través de los diversos órganos colegiados a que se ha hecho mención.

La sanción de la Ley $N^{\circ} 20.424$, tras cinco años de análisis y debates en el Congreso chileno, constituyó una innovación importante en el esquema señalado.

En efecto, el aludido cuerpo normativo, tras destacar (artículo $1^{\circ}$ ) la autoridad del Presidente de la República "...en todo cuanto tiene por objeto la seguridad externa de la República, de acuerdo con la Constitución y las leyes..." estableció que a los "...efectos de ejercer dicha autoridad y conducir la defensa nacional, el Presidente de la República dispone de la colaboración directa e inmediata del Ministro de Defensa Nacional, en los términos establecidos por la Constitución y las leyes...".

73 Ley № 20.424, Diario Oficial, Santiago de Chile, 4 de febrero de 2010.

74 Ley № 19.974, Diario Oficial, Santiago de Chile, 2 de octubre de 2004.

75 Ley № 20.424. Loc. Cit. 
El aludido artículo asignó al Presidente de la República la facultad de disponer de las fuerzas de aire, mar y tierra, organizarlas y distribuirlas de acuerdo con las necesidades de la seguridad nacional, ratificando la dependencia de dichas fuerzas respecto del Ministerio de Defensa, y disponiendo que en caso de crisis internacional que afectare la seguridad exterior y en caso de guerra exterior, el Presidente de la República asumiría la jefatura suprema de las Fuerzas Armadas entregando al Jefe del Estado Mayor Conjunto la conducción estratégica de los medios asignados.

Tras ratificar el artículo $2^{\circ}$ la dependencia de las Fuerzas Armadas respecto del Ministerio de Defensa Nacional, el artículo 3ㅇaa asignó al referido ministerio el carácter de órgano superior de colaboración del Presidente de la República en las funciones de gobierno y administración de la Defensa Nacional, encomendándole, en consecuencia, la propuesta y la evaluación de la política de defensa, la política militar y las planificaciones primaria y secundaria de la Defensa Nacional, así como el estudio, la propuesta y la evaluación de las políticas y normas aplicables a los órganos integrantes del sector Defensa y el control relativo a su cumplimiento, el estudio de las necesidades financieras y presupuestarias del aludido sector y la propuesta del anteproyecto de presupuesto anual, y la asignación, la administración y el control del uso de los recursos asignados a los organismos correspondientes al sector referido.

Nos encontramos evidentemente, en el contexto latinoamericano, con un robusto ministerio, con facultades fundamentales tanto en materia de formulación y evaluación de la política de defensa, la política militar y las planificaciones de defensa y militar, como en materia de fiscalización de actividades, de formulación de la propuesta presupuestaria, e incluso supervisión en materia de inversión de los recursos.

Cabe señalar, además, que el artículo $5^{\circ}$ encomendó al ministro otras funciones. Entre ellas, habremos de destacar especialmente la facultad de aprobar la planificación secundaria, es decir, la planificación estratégica militar elaborada por el Estado Mayor Conjunto.

Como expresión de los intereses institucionales de las Fuerzas Armadas, persistió la Junta de Comandantes en Jefe, a la que el artículo 10 definió como "... el órgano consultor del Ministro de Defensa Nacional en materias comunes de las Fuerzas Armadas relativas al desarrollo y empleo de los medios militares...".

El referido artículo estableció el requerimiento obligatorio de la opinión de la aludida Junta, respecto de aspectos importantes como la planificación primaria y secundaria de la defensa nacional y respecto de la doctrina y reglamentación conjunta, entre otros aspectos fundamentales de la defensa.

Se advertirá que la opinión de la Junta no es vinculante. Aparece como un cierto contrapeso, bien que limitado, a las facultades que son conferidas por la ley al Ministerio de Defensa y al Estado Mayor Conjunto.

La ley no solo asignó al ministerio facultades fundamentales en los aspectos señalados, sino también lo dotó de los medios técnicos necesarios para ejercerlas con 
eficacia.

En efecto, creó un órgano sustantivo de elaboración de políticas de defensa, la Subsecretaría de Defensa, a la cual el artículo 15 asignó, entre otras, las atribuciones de sugerir al Ministro la política de defensa nacional y la política militar, y encargarse de su actualización y explicitación periódica, de efectuar el análisis político y estratégico para la elaboración, actualización y proposición al ministro de la apreciación de los riesgos y amenazas para el país en el ámbito de su seguridad exterior, de sugerir al ministro la planificación primaria de la defensa nacional y su actualización periódica, asegurando la correspondencia de la planificación secundaria con aquélla; la de coordinar, en conformidad con las instrucciones del ministro, la acción internacional de los organismos del sector defensa, la propuesta al ministro de las orientaciones para las adquisiciones de las Fuerzas Armadas, incluyendo aquéllas para sistemas de armas y otros equipos.

Como puede advertirse, nos encontramos ante el núcleo duro de la política de defensa. Por ello, también parece una decisión legislativa acertada la de establecer la dependencia de la Academia Nacional de Estudios Políticos y Estratégicos (ANEPE) respecto de la Subsecretaría.

También parece acertado, como se dispone en el artículo 18, que se establezca una relación funcional respecto de la aludida Subsecretaría de las empresas estatales chilenas de producción de material bélico, FAMAE, ASMAR y ENAER.

Otro cambio importante de la ley en comentario es la sustitución de las antiguas Subsecretarías de Guerra, Marina y Aviación, así como de la Dirección Administrativa del Ministerio, por una Subsecretaría para las Fuerzas Armadas, que además de sustituir a los órganos referidos, adquirió mayores facultades que sus predecesoras.

También la ley incrementó sustancialmente las funciones del ahora denominado Estado Mayor Conjunto, establecidas en el artículo 25.

Definido ahora como el organismo de trabajo y asesoría permanente del conjunto de las Fuerzas Armadas, siendo órgano de asesoría y trabajo en la conducción estratégica para enfrentar las situaciones que puedan demandar los estados de excepción constitucional y, en particular, los casos de guerra externa o crisis internacional que afectare a la seguridad exterior de la República, asignándosele ahora con exclusividad bien que sujeto a aprobación del ministro- el desempeño de las funciones propias del accionar conjunto, destacándose la elaboración de la planificación secundaria, la doctrina conjunta, el entrenamiento conjunto, siendo también de interés su participación en los proyectos de adquisición e inversión conjuntos. Incrementan la importancia de este órgano las importantes funciones operacionales que le son asignadas en la ley.

El artículo 26, al par que establece su dependencia respecto del ministro de Defensa, estableció además que el órgano en cuestión "...ejercerá el mando militar de las fuerzas terrestres, navales, aéreas y conjuntas asignadas a las operaciones, en conformidad a la planificación secundaria de la defensa nacional....". 
Otro aspecto de importancia dentro de las funciones y responsabilidades ahora asignados al Ministerio, es el contemplado en el artículo 33, en cuanto establece que dicho órgano "...será responsable de supervisar la inversión de los recursos asignados a los organismos, servicios e instituciones del sector defensa..." disponiéndose además que las empresas de producción bélicas serán también evaluadas por el Ministerio.

En definitiva, no caben dudas respecto a que después de la sanción de la ley referida, es el Ministerio de Defensa quien en Chile toma las decisiones relativas a la defensa.

Otro hecho importante ha estado constituido por la sanción de la Ley № $21.174^{76}$ estableciendo "un nuevo mecanismo de financiación de las capacidades estratégicas de las Fuerzas Armadas".

El nuevo cuerpo normativo concluyó con el financiamiento del equipamiento de las Fuerzas Armadas de Chile a través de un porcentaje del $10 \%$ de los ingresos por ventas al exterior de la empresa estatal de cobre CODELCO, mecanismo de limitados controles y cuyos ingresos dependían en definitiva de factores externos a la defensa, sustituyéndolo por la creación de un Fondo Plurianual para las Capacidades Estratégicas de la Defensa, y un Fondo de Contingencia Estratégico, cubriendo el primero de ellos tanto la inversión en material bélico, en base a un plan cuatrienal de inversiones destinado a financiar la obtención de las capacidades estratégicas determinadas por el planeamiento, como el mantenimiento del material bélico que fuera adquirido, y destinado el segundo para cubrir contingencias de guerra o crisis internacional, estableciéndose controles para la gestión de los aludidos fondos.

En otro orden de ideas, cabe destacar el dictado por el Órgano Ejecutivo del Decreto Supremo № 265/201977, a través del cual se autorizó la colaboración de las Fuerzas Armadas con las autoridades civiles y policiales competentes para actuar en relación a actividades que se vincularan al narcotráfico y crimen organizado transnacional, en el marco de las facultades que la Constitución y la ley les otorgaran, en zonas fronterizas del territorio nacional, debiendo el ministro del Interior y Seguridad Pública evaluar la forma en que las policías emplearán la colaboración mencionada, coordinándose con el ministro de Defensa Nacional para la eficacia de tal colaboración, que incluiría la prestación de apoyo logístico, de transporte y tecnológico, en zonas fronterizas del territorio nacional.

Este decreto no dejó de suscitar polémicas.

Como ejemplo, el exsubsecretario de Defensa y académico Marcos Robledo ${ }^{78}$ destacó que la formación que reciben las instituciones militares ha traído como consecuencia el aumento de la violencia en zonas donde se les ha encargado colaborar con la lucha anti

76 Ley № 21.174. Diario Oficial, Santiago de Chile, 26 de septiembre de 2019.

77 Decreto Supremo № 265/2019, Diario Oficial, Santiago de Chile, 13 de agosto de 2019.

78 ANDRADE, Eduardo. Militarización contra el narcotráfico: un paso atrás en el debate latinoamericano, Radio Universidad de Chile, Santiago de Chile, 10 de julio de 2019 [En línea] Consultado el 27 de febrero de 2020, disponible en https://radio.uchile.cl/2019/07/10/militarizacion-contra-el-narcotrafico-un-pasoatras-en-el-debate-latinoamericano/ 
narcotráfico. Asimismo, el académico Felipe Agüero ${ }^{79}$ señaló que lo que se requería, ante un incremento del narcotráfico, era mejorar los instrumentos con que se contaba para esos fines -Carabineros, Policía de Investigaciones-.

Por otra parte, el 18 de octubre de 2019 se agravaron en Santiago de Chile las protestas contra el alza del precio del metro, produciéndose desórdenes que según todos los indicios expresaban un descontento social más profundo.

El 19 de octubre, fue dictado el Decreto Supremo № 472/201980, en virtud del cual se declaró el estado de excepción constitucional de emergencia, en las Provincias de Santiago y de Chacabuco, así como en las comunas de Puente Alto y San Bernardo de la Región Metropolitana, por un plazo de 15 días, conforme a lo dispuesto en el artículo 8ㅇ de la Ley № 18.415, designándose como Jefe de Defensa Nacional en la referida zona a un alto Oficial del Ejército, a quien se asignó el mando de las Fuerzas Armadas y del Orden y Seguridad Pública.

Es, asimismo, de sanción inminente un Proyecto de Fortalecimiento y modernización del Sistema de Inteligencia de Estado $(\mathrm{SIE})^{81}$, que incorpora como miembros del Sistema de Inteligencia a Gendarmería de Chile (Servicio Penitenciario) y al Servicio Nacional de Aduanas, estableciendo además que la Unidad de Análisis Financiero (UAF) y el Servicio de Impuestos Internos (SII) integren el Sistema al solo efecto de aportar análisis de inteligencia estratégica.

Se crea un Consejo Asesor de Inteligencia, constituido por el ministro del Interior y Seguridad Pública, el ministro de Defensa Nacional, el subsecretario del Interior, y los jefes de los organismos que conforman el SIE, para asesorar directamente al Presidente de la República en materia de inteligencia.

Se fortalece la autoridad del Director de la Agencia Nacional de Inteligencia, organismo central del SIE, creándose además el cargo de Subdirector, incrementándose las limitadas facultades de la Comisión de Control de la Cámara de Diputados.

Cabe destacar, asimismo, la presentación y trámite por el Órgano Ejecutivo de un proyecto de ley de reforma de la Ley Orgánica Constitucional de las Fuerzas Armadas, a fin de establecer el rol de éstas en materia de protección de la infraestructura crítica cuando fuera indispensable para la seguridad nacional. Se trata en definitiva de asignar a dichas fuerzas una nueva función en seguridad interior, bien que por tiempo limitado -treinta días prorrogables una vez por igual período- "...cuando exista un riesgo para la seguridad de la Nación, fuera de los casos de estado de excepción constitucional..." ${ }^{82 .}$

En definitiva, Chile es un país caracterizado por una misión de las Fuerzas Armadas

79 Ibídem.

80 Decreto Supremo № 472/2019. Diario Oficial, Santiago de Chile, 18 de octubre de 2019.

81 PROYECTO DE LEY QUE FORTALECE Y MODERNIZA EL SISTEMA DE INTELIGENCIA DEL ESTADO, Mensaje № 192/366, Boletín № 12234-02, Senado de Chile, Santiago de Chile, 2018.

82 PROYECTO DE LEY DE REFORMA DE LA LEY ORGÁNICA CONSTITUCIONAL DE LAS FUERZAS ARMADAS, Mensaje № 534/365, Boletín N 13.088-02, Senado de Chile, Santiago de Chile, 2019. 
clara y orientada hacia la defensa y que ha realizado grandes avances hacia el control civil, en los últimos años, y que al mismo tiempo puede mostrar una política de defensa exitosa en cuanto al desarrollo de adecuadas capacidades para la defensa. Cabe señalar, no obstante, que en los últimos años se han producido medidas de limitado involucramiento de las Fuerzas Armadas en seguridad pública.

\subsection{Colombia}

Junto con Venezuela y México, Colombia integró el reducido núcleo de países latinoamericanos que lograron transcurrir la Guerra Fría sin golpes militares, aunque no sin que dicho conflicto dejara de ejercer influencia en sus Fuerzas Armadas y su estructura de defensa.

Aunque la historia colombiana estuvo caracterizada por las guerras civiles padecidas por el país durante la mayor parte del siglo XIX, también sostuvo conflictos armados limitados con Perú, antiguamente la guerra grancolombo-peruana (1828-29) y muy posteriormente, los episodios bélicos de La Pedrera (1911) y la Guerra de Leticia (1932-1933), además de una simbólica participación en la Segunda Guerra Mundial y una participación más activa en la Guerra de Corea.

No obstante, los conflictos internos han constituido la mayor actividad de las Fuerzas Armadas de Colombia, que además de diversos conflictos civiles han enfrentado a las organizaciones insurgentes FARC-EP (1964-2016), ELN (1964-actualidad), EPL (1967-actualidad), M-19 (1970-1990), Movimiento Armado Quintín Lame (1984-1991), y la organización contrainsurgente Autodefensas Unidas de Colombia (1960, presuntamente desmovilizada en 2006) pero que continuó con diversas expresiones denominadas por el Gobierno como Bandas Criminales (BACRIM), etc.

Tales circunstancias han determinado una organización militar configurada por su organización y despliegue para la seguridad interior y particularmente para la contrainsurgencia, y han transformado a Colombia en uno de los países latinoamericanos con mayor grado de violencia.

La firma del "Acuerdo Final para la Terminación del Conflicto y la Construcción de una Paz Estable y Duradera", del 12 de noviembre de 2016, entre el Gobierno y las FARC$E P$, principal organización insurgente del país, culminando un trabajoso proceso de paz, más allá de las dificultades para su implementación y la subsistencia de organizaciones y sectores violentos, brinda expectativas de disminución de la violencia y una eventual reconfiguración de las Fuerzas Armadas para la función de defensa, aun cuando no fuera total. Cabe señalar que el Acuerdo referido no contiene previsiones sobre reconfiguración de los sistemas de defensa y seguridad tras el conflicto, como las contenidas en los Acuerdos de Paz celebrados entre el Gobierno de El Salvador y el FMLN y el Gobierno de Guatemala y la UNRG.

La Constitución Política de Colombia de $1991^{83}$ y modificatorias, comprende dentro

83 CONSTITUCIÓN POLÍTICA DE 1991 DE LA REPÚBLICA DE COLOMBIA, Departamento Administrativo de 
de la categoría "Fuerza Pública" a las Fuerzas Militares y a la Policía Nacional (artículo 216). Establece además que las Fuerzas Militares tienen como finalidad primordial la defensa de la soberanía, la independencia, la integridad del territorio nacional y del orden constitucional (art. 217) bien que en la práctica, como se ha visto, la seguridad interna del Estado ha sido su finalidad fundamental.

Colombia cuenta con un Ministerio de Defensa, cargo que en las últimas décadas ha correspondido casi exclusivamente a funcionarios civiles. De él dependen tanto las Fuerzas Armadas -Comando General de las Fuerzas Militares, y los Comandos del Ejército, de la Armada y de la Fuerza Aérea- como la Dirección Nacional de la Policía Nacional, aunando defensa nacional con seguridad pública, confusión característica de diversos gobiernos latinoamericanos durante la Guerra Fría, explicada en Colombia por la función predominantemente contrainsurgente de sus Fuerzas Armadas en las últimas décadas.

Integran también el Ministerio -además del Despacho del Ministro y la Secretaría de Gabinete de aquél- el Viceministerio de Políticas y Asuntos Internacionales, el Viceministerio para la Estrategia y Planeación, y el Viceministerio "GSED” y Bienestar, y la Secretaría General. (Decreto 1070/2015) ${ }^{84}$.

Cabe señalar que el GSED (Grupo Social y Empresarial del Sector Defensa) constituye un órgano de orientación y coordinación de las entidades adscriptas y vinculadas al sector Defensa (Decreto 4483/2008 ${ }^{85}$ y Decreto 4177/2011 ${ }^{86}$ ) que incluyen entes previsionales, vivienda militar, defensa civil, INDUMIL -fabricante de material bélico- CIAC -industria aeronáutica- servicio aéreo a territorios nacionales SATENA, etc.

Corresponde destacar, asimismo, que las direcciones dependientes de los viceministerios alternan competencias en materia de defensa y de seguridad pública, dado que ambos aspectos integran las competencias del Ministerio.

En cuanto a las competencias del ministro, tal como surgen del art. 10 del Decreto $49 / 2003^{87}$, modificado por sus similares $3123 / 2007^{88}$, 4890 de $2011^{89}$, y 2758 de $2012^{90}$, y de los artículos 1, 2, 3, 4, 5 y 8 del Decreto 1512/200091, comprenden lo relativo a la dirección del Ministerio, la coordinación y la orientación del desarrollo de la política para la defensa de la soberanía, la independencia, la integridad territorial, la seguridad y la tranquilidad públicas, así como para el mantenimiento del orden constitucional y la garantía de la convivencia democrática; y la formulación de las políticas generales del Sector; como también, con la inmediata colaboración del Comandante General de las

la Función Pública, Bogotá [En línea]Consultado el 5 de enero de 2020, disponible en: https://www. funcionpublica.gov.co/eva/gestornormativo/norma pdf.php?i=4125

84 Decreto № 1070/2015, Diario Oficial, Bogotá, 26 de mayo de 2015.

85 Decreto № 4483/2008, Diario Oficial, Bogotá, 27 de noviembre de 2008.

86 Decreto № 4177/2011, Diario Oficial, Bogotá, 3 de noviembre de 2011.

87 Decreto № 499/2003, Diario Oficial, Bogotá, 14 de enero de 2003.

88 Decreto № 3123/2007, Diario Oficial, Bogotá 17 de agosto de 2007.

89 Decreto № 4890/2011, Diario Oficial, Bogotá, 26 de diciembre de 2011.

90 Decreto № 2758/2012, Diario Oficial, Bogotá, 29 de diciembre de 2012.

91 Decreto № 1512/2000, Diario Oficial, Bogotá, 11 de agosto de 2000. 
Fuerzas Militares, los Comandantes de Fuerza, el Director General de la Policía Nacional de Colombia, los Viceministros y el Secretario General, la estrategia para el desarrollo de los planes y programas en materia de defensa y seguridad, cabiéndole también la preparación del anteproyecto presupuestario del sector y la dirección de la ejecución presupuestaria. En definitiva, la formulación y ejecución de las políticas en materia de defensa nacional y de seguridad pública. Cabe señalar que Colombia emplea el método de planeamiento militar por capacidades, vigente entre otros países de la región, en Argentina, Brasil y Chile.

Cabe destacar también la existencia de un ente descentralizado conjunto creado por Decreto 4746 de 200592, la Agencia Logística de las Fuerzas Militares, cuyo objeto es el de ejecutar las actividades de apoyo logístico y abastecimiento de bienes y servicios requeridos para atender las necesidades de las Fuerzas Militares (art. 6ㅇ, complementado por los Decretos $1753 / 2017^{93}$ y 1754/2017) ${ }^{94}$. Integran sus funciones (art. 7으), la adquisición de los bienes y servicios, y la realización de las obras de infraestructura requeridos por las Fuerzas Militares, así como la administración de las instalaciones destinadas al bienestar del personal militar y la realización de las contrataciones necesarias a tales efectos. Esta entidad tiene dirección militar e integra el sector GSED.

En definitiva, el ministerio tiene competencias no solo en materia administrativa, sino también técnico-militares y policiales, bien que los cargos relativos a aspectos técnico-militares están cubiertos con personal militar. No obstante, el ministerio carece de competencias en materia operativa, aspecto importante tratándose de fuerzas que operan constantemente en el territorio del país, carencia que incluye al planeamiento estratégico operacional, contándose con comandos estratégicos operacionales conjuntos y específicos. En el aspecto operacional, el Comandante General de las Fuerzas Militares y los aludidos comandos operacionales llegan directamente al presidente. En ese aspecto, las Fuerzas Armadas presentan un significativo grado de autonomía.

Respecto de las Fuerzas Militares y de la Policía Nacional, su mando corresponde al Presidente de la República, quien lo ejerce directamente o a través del ministro de Defensa Nacional, quien a su vez, respecto de las Fuerzas Militares, lo ejerce a través del Comandante General de las Fuerzas Militares, y respecto de la Policía Nacional, a través del Director General de dicha institución.

Colombia cuenta además con un Consejo de Seguridad Nacional -Decreto 4748 de $2010^{95}$ - que constituye (artículo 2º) el máximo órgano asesor del Presidente de la República para la toma de decisiones en materia de seguridad nacional, asesorándolo en el proceso de formulación, implementación y seguimiento de políticas de seguridad nacional, con el objetivo de coordinar los esfuerzos de los Ministerios y otras entidades del Estado.

Está integrado (artículo 3) por el Presidente de la República, quien lo preside, y por los ministros del Interior y de Justicia; Relaciones Exteriores; Defensa Nacional; de

92 Decreto № 4746/2005, Diario Oficial, Bogotá, 30 de diciembre de 2005.

93 Decreto № 1753/2017, Diario Oficial, Bogotá 27 de octubre de 2017.

94 Decreto № 1754/2017, Diario Oficial, Bogotá, 27 de octubre de 2017.

95 Decreto № 4748/2010, Diario Oficial, Bogotá, 23 de diciembre de 2010. 
Hacienda y Crédito Público, el Director del Departamento Administrativo de la Presidencia de la República; el Director del DAS, órgano hoy suprimido y sustituido por la Dirección Nacional de Inteligencia (DNI), el Comandante General de las Fuerzas Militares; el Director de la Policía Nacional; el Alto Consejero Presidencial para la Convivencia Ciudadana; y el Alto Asesor Presidencial para la Seguridad Nacional, quien es su secretario técnico.

Entre las facultades del Consejo se encuentran (artículo 4을 las de asesorar al Presidente de la República en materia de defensa y seguridad nacional; asesorar al Presidente de la República en el establecimiento de las prioridades de seguridad nacional; proponer al Presidente de la República escenarios y opciones para la toma de decisiones en materia de seguridad nacional; asesorar al Presidente de la República en la formulación de políticas institucionales en materia de seguridad nacional, asesorar al Presidente de la República sobre las implicaciones de las políticas sectoriales relacionadas con la seguridad nacional; asesorar al Presidente de la República en el manejo de crisis relacionadas con la seguridad nacional; asesorar al Presidente de la República en la formulación de requerimientos de inteligencia; y asesorar al Presidente de la República en el establecimiento de las políticas de seguridad de la información del Gobierno Nacional.

En resumen, cabe concluir que en Colombia existe un Ministerio de Defensa de conducción civil y competencias en materia administrativa y también técnico-militares, aunque no operacionales. La competencia militar es amplia, en mayor medida en la práctica que lo que surge de las normas, y existe una virtual confusión entre defensa nacional y seguridad interior, lo que inexorablemente lleva a la militarización de esta última

Con relación al futuro de la Fuerza Pública colombiana post-conflicto armado, resulta de interés entre otras fuentes el documento "Transformación y Futuro de la Fuerza Pública 2010-2030", elaborado durante la pasada administración colombiana.

En él se destaca la necesidad de evitar, tras la paz, drásticas reducciones en el presupuesto y en la estructura de la referida Fuerza Pública.

Se afirma que Colombia procurará mantener las capacidades que le permitan enfrentar exitosamente un conflicto externo y un conflicto interno simultáneamente, preservando la experiencia y capacidades logradas durante el conflicto armado interno, previendo no obstante la concentración de las Fuerzas Militares en las funciones de defensa externa, protección de los ámbitos terrestre, marítimo, aéreo, y ciberespacial, y operaciones de paz, manteniendo su aptitud de garantizar la seguridad interior, concentrándose la Policía Nacional por su parte en el mantenimiento de la seguridad interior y la convivencia pacífica en el país, luchando tanto contra el delito organizado, como contra el delito común.

En suma, Colombia cuenta con un Ministerio de Defensa con adecuadas facultades y buen nivel técnico. Cabe advertir una excepción a tales facultades en materia operativa, en la cual es el Comandante General de las Fuerzas Militares quien se vincula con el Presidente de la Nación, operando como un sistema cerrado. Mientras dicho ministerio cuenta con una burocracia civil formada, los aspectos técnicos militares son cubiertos por personal militar. 
La misión militar resulta de suma amplitud por el amplio involucramiento de las Fuerzas Armadas en seguridad interior, a lo que se une la circunstancia de depender la Policía Nacional, única policía de Colombia, del Ministerio de Defensa, de lo que resulta una sustancial militarización de la seguridad interior. Tales circunstancias dificultan el control civil.

\subsection{Perú}

Perú se caracteriza por poseer Fuerzas Armadas multifuncionales y con amplia participación en seguridad interior.

Conforme a la Constitución de $1993^{96}$, la misión de las Fuerzas Armadas definida en los artículos 137 y 165 incluye garantizar la independencia, la soberanía y la integridad territorial de la República -misión militar clásica- y, además, la de asumir el control del orden interno en caso de emergencia si así lo dispone el Poder Ejecutivo.

Las leyes amplían significativamente esta misión. Así, tienen a su cargo la conducción de la lucha contra el narcotráfico y terrorismo en caso de emergencia (artículo 50 inciso j), Ley № $24.150^{97}$ ), así como prestar apoyo a la Policía Nacional en caso de tráfico ilícito de drogas, terrorismo, o protección de instalaciones estratégicas para el desarrollo del país, servicios públicos esenciales, y cuando la capacidad de la policía sea sobrepasada en su capacidad de control del orden interno o fuera previsible que así sucediera (Decreto Legislativo № 1095/201098, artículo 4우).

Integran también las misiones de las Fuerzas Armadas, las de participar en la ejecución de las políticas de Estado en materia de desarrollo económico y social del país, defensa civil, ciencia y tecnología, objetos arqueológicos e históricos, asuntos antárticos, asuntos amazónicos y de protección del medio ambiente, de acuerdo con la normatividad legal vigente (Ley del Ejército del Perú, Decreto Legislativo № 1137/2012 ${ }^{99}$, artículo 4은 inciso 6). También, las de participar en la ejecución de las políticas de Estado en materia de asuntos antárticos, y asuntos amazónicos, así como conducir el Sistema de Información y Monitoreo del Tráfico Acuático y ejercer la autoridad marítima, fluvial y lacustre (Decreto Legislativo № 1138/2012 ${ }^{100}$, artículo 4으, incisos 7, 8 y 10), y dirigir las actividades relacionadas con el Poder Aéreo y la defensa de los intereses aeroespaciales (Decreto Legislativo № 1139/2012 ${ }^{101}$, artículo 1ㅇ).

En materia de control civil, el fortalecimiento de la democracia que siguió a la experiencia dictatorial fujimorista dio lugar a un conjunto de normas como la Ley $\mathrm{N}^{\circ}$

96 Constitución Política del Perú, promulgada el 29 de diciembre de 1993, Edición del Congreso de la República, Lima, Septiembre de 2017 [En línea ] Consultado el 8 de enero de 2020, disponible en http:// www.congreso.gob.pe/Docs/files/documentos/constitucionparte1993-12-09-2017.pdf

97 Ley № 24.150, El Peruano, Lima, 7 de junio de 1985.

98 Decreto Legislativo № 1095/2010, El Peruano, Lima, 1 de septiembre de 2010.

99 Decreto Legislativo № 1137/2012, El Peruano, Lima 10 de diciembre de 2012.

100 Decreto Legislativo № 1138/2012 El Peruano, Lima, 10 de diciembre de 2012.

101Decreto Legislativo № 1139/2012, El Peruano, Lima, 10 De Diciembre de 2012. 
$28.478^{102}$ del Sistema de Seguridad y Defensa y la Ley $N^{\circ} 29.605^{103}$, relativa a la naturaleza jurídica, función, competencias y estructura orgánica básica del Ministerio de Defensa, que implementaron un sistema que caracterizamos en un trabajo anterior como una organización de la defensa "...que favorece la obtención de la ... conducción política de la defensa..." 104 .

Merece señalarse que tras la asunción como presidente del teniente coronel (R.) Ollanta Moisés Humala Tasso -que gobernó el país entre 2011 y 2016- se realizaron importantes reformas en la legislación sobre defensa y seguridad a través de Decretos Legislativos, dictados por el Órgano Ejecutivo en base a facultades conferidas por el Órgano Legislativo, que introdujeron modificaciones en el sistema antes mencionado.

La nueva organización fue instrumentada a través de los Decretos Legislativos $\mathrm{N}^{\circ}$ $1129^{105}, \mathrm{~N}^{\circ} 1134^{106} \mathrm{~N}^{\circ} 1136^{107}, \mathrm{~N}^{\circ} 1137, \mathrm{~N}^{\circ} 1138, \mathrm{y} \mathrm{N}^{\circ} 1139$ - entre otros.

El Decreto Legislativo $N^{\circ} 1129$ definió en su artículo $3^{\circ}$ al Sistema de Defensa Nacional como “...el conjunto interrelacionado de principios, normas, procedimientos, técnicas, instrumentos y elementos del Estado, cuya finalidad es garantizar la Seguridad Nacional mediante la concepción, planeamiento, dirección, preparación, ejecución y supervisión de acciones en todos los campos de la Defensa Nacional..." sin definir Defensa Nacional ni Seguridad Nacional pero asignando idéntica extensión conceptual a la primera y a la segunda.

Por otra parte, el artículo $5^{\circ}$ creó un Consejo de Seguridad y Defensa Nacional, al que caracterizó como el órgano del más alto nivel de decisión política y de coordinación estratégica en materia de Seguridad y Defensa Nacional.

En cuanto a su estructura, el artículo $6^{\circ}$ estableció que “...El Consejo de Seguridad y Defensa Nacional está conformado por: a) El Presidente de la República, quien ejerce la Presidencia del Consejo; b) El Presidente del Consejo de Ministros; c) El Ministro de Relaciones Exteriores; d) El Ministro de Defensa; e) El Ministro de Economía y Finanzas; f) El Ministro del Interior; g) El Ministro de Justicia y Derechos Humanos; h) El Jefe del Comando Conjunto de las Fuerzas Armadas; i) El Director de la Policía Nacional del Perú; j) El Director Ejecutivo de la Dirección Nacional de Inteligencia...".

Con relación a sus funciones, dispuso el artículo $7^{\circ}$ que “...Corresponde al Consejo de Seguridad y Defensa Nacional aprobar: a) Los Objetivos y la Política de Seguridad y Defensa Nacional; b) Las normas y lineamientos técnicos para la implementación y evaluación de la política de Seguridad y Defensa Nacional; c) Las directivas sobre Seguridad y Defensa Nacional; d) Las normas y disposiciones relacionadas a la Movilización Nacional;

102Ley № 28.478, El Peruano, Lima, 27 de marzo de 2005.

103Ley № 29.605, El Peruano, Lima, 22 de octubre de 2010.

104UGARTE, José Manuel. 2013. Op. Cit. p. 76.

105Decreto Legislativo № 1129/2012, El Peruano, Lima, 7 de diciembre de 2012

106Decreto Legislativo № 1134/2012, El Peruano, Lima, 10 de diciembre de 2012 y 16 de diciembre de 2012

(Fe de erratas).

107Decreto Legislativo № 1136/2012, El Peruano, Lima, 10 de diciembre de 2012. 
e) Las medidas para el perfeccionamiento del Sistema de Defensa Nacional; f) Los demás aspectos relacionados con la Seguridad y la Defensa Nacional...".

Con relación al Decreto Legislativo N 1134 que aprueba la organización y funciones del Ministerio de Defensa, cabe señalar que aunque con facultades algo disminuidas en relación a las que poseía anteriormente a la reforma, continúa siendo en el contexto latinoamericano un Ministerio de Defensa con facultades adecuadas.

Así, en orden de importancia, el artículo $9^{\circ}$, segundo párrafo, estableció que el Ministro de Defensa “...Ejerce constitucionalmente la conducción de las Fuerzas Armadas, conforme a los lineamientos dispuestos por el Presidente de la República..."

Tiene asimismo las facultades de “...Normar, disponer y supervisar el diseño, magnitud, clasificación y distribución de los recursos materiales de las Fuerzas Armadas, de conformidad con las directrices del Presidente de la República..." (artículo $10^{\circ}$ inciso 10); " ...Dirigir el proceso de planeamiento estratégico y aprobar los planes estratégicos del sector Defensa, en el marco de la normatividad sobre Seguridad y Defensa Nacional y del Planeamiento Estratégico Integral..." (artículo 10 inciso 7); le corresponde también “...Supervisar la ejecución de los planes y programas de inversión y estandarización del equipamiento de las Fuerzas Armadas..." (artículo 10 inciso 13); "Aprobar la lista general de contrataciones consideradas estratégicas en materia de defensa, que sean efectuadas por la Agencia de Compras..." (artículo $10^{\circ}$ inciso 13), siendo de destacar que corresponde además al Ministerio la supervisión de la referida Agencia, así como el cumplimiento del Plan Estratégico de Compras (artículo $6^{\circ}$ inciso 12) “...Establecer los lineamientos educativos de las Fuerzas Armadas..." (artículo $6^{\circ}$ inciso 12); entre otros muchos aspectos.

Ello evidencia que en Perú el Ministerio de Defensa no está limitado a aspectos meramente administrativos, sino que también dirige o interviene en aspectos técnicooperativos.

Por otra parte, el Comando Conjunto de las Fuerzas Armadas, órgano responsable de "...realizar el planeamiento, preparación, coordinación y conducción de las operaciones y acciones militares de las Fuerzas Armadas...".depende del Ministerio de Defensa, y su Jefe, del Ministro de Defensa (artículo 14). Lo mismo sucede en el caso del Ejército del Perú (artículo 15), Marina de Guerra del Perú (artículo 16) y Fuerza Aérea del Perú (artículo 17).

Continúa poseyendo el Ministerio de Defensa un Viceministro de Políticas para la Defensa y un Viceministro de Recursos para la Defensa, además de un Secretario General.

En definitiva, cabe considerar que con el Decreto Supremo $\mathrm{N}^{\circ}$ 061-2016-PCM ${ }^{108}$ dictado como consecuencia de la Ley $\mathrm{N}^{\circ} 27.658^{109}$ que dispuso la fusión por absorción de la SEDENA y del Centro de Estudios Nacionales (CAEN) en el Ministerio de Defensa, desapareció la objeción fundamental que merecía la reforma, que era la superposición en buena parte de las facultades de la SEDENA, organismo de conducción militar, con el

108 Decreto Supremo Nº61-2016-PCM, El Peruano, Lima, 16 de agosto de 2016.

109 Ley № 27.658, El Peruano, Lima, 30 de enero de 2002. 
Ministerio de Defensa.

Además de la ya señalada multifuncionalidad de las Fuerzas Armadas peruanas, cabe señalar desde el punto de vista del control civil que habiendo contado Perú inicialmente con ministros de Defensa militares, y alternándose posteriormente militares con civiles, entre 2006 y 2018 contó ininterrumpidamente con ministros civiles.

La asunción a partir del 2 de abril 2018 como ministro de Defensa del general de división (R.) José Modesto Huerta Torres, se vio acompañada por la cobertura por militares de la totalidad de los cargos de importancia del Ministerio: el general de división (R.) Hernán Felipe Flores Ayala ocupó el cargo de Viceministro de Políticas para la Defensa, mientras que el vicealmirante (R.) Gonzalo Ríos Polastri, el de Viceministro de Recursos para la Defensa, sucediendo a un teniente general de la Fuerza Aérea del Perú. Ocupaba asimismo la Inspectoría General del Ministerio, el vicealmirante (R. ) Humberto Fredy León Rabines Gironda.

Tal característica se ha mantenido. En marzo de 2020 el general de división (R.) Walter Roger Martos Ruiz era el Ministro de Defensa, mientras que el teniente general FAP (R.) Javier Enrique Ramírez Guillén ocupaba el cargo de Viceministro de Recursos para la Defensa, el general de división (R.) Hernán Felipe Flores Ayala el de Viceministro de Políticas para la Defensa, y el general de brigada (R.) Augusto Soto Castagnola el de Inspector General del Ministerio.

Sin poner en duda el desempeño ni la idoneidad de los referidos funcionarios, la experiencia en materia de relaciones civiles-militares en Latinoamérica hace inevitable concluir que en países con largos períodos de gobierno militar e instituciones débiles, la circunstancia reseñada no aparece como una buena señal para el fortalecimiento de la conducción política de la defensa.

\subsection{Ecuador}

Cabe destacar que las Fuerzas Armadas de Ecuador, aun en épocas de vigencia del sistema democrático, ejercían a través de un conjunto de normas, entre las que sobresalía la Ley de Seguridad Nacional ${ }^{110}$ un verdadero rol tutelar y de arbitraje político respecto de la democracia ecuatoriana y de las autoridades electas, lo que se manifestó en la deposición de los presidentes Abdalá Bucaram (1996-1997) y Jamil Mahuad (1998-2000). Cabe señalar que el coronel Lucio Gutiérrez, figura fundamental en el derrocamiento de Mahuad, fue posteriormente electo Presidente Constitucional de Ecuador encabezando el partido político, de inspiración y composición mayoritariamente militar, "Sociedad Patriótica 21 de enero", pero fue destituido por el Congreso como consecuencia del alzamiento popular en su contra, conocido como la "Revolución de los Forajidos" (20 de abril de 2005).

La elección del presidente Dr. Rafael Correa Delgado (2007-2017) significó un cambio en dicha situación.

110 Ley № 275 DE SEGURIDAD NACIONAL, Registro Oficial, Quito, 9 de agosto de 1979 
En primer lugar, la Constitución sancionada en $2008^{111}$ implicó importantes reformas en materia de misión de las fuerzas armadas.

Así, en la Sección Tercera, Capítulo Tercero, estableció el artículo 158 que “... Las Fuerzas Armadas tienen como misión fundamental la defensa de la soberanía y la integridad territorial. La protección interna y el mantenimiento del orden público son funciones privativas del Estado y responsabilidad de la Policía Nacional....".

Asimismo, el artículo 162 dispuso que “...Las Fuerzas Armadas solo podrán participar en actividades económicas relacionadas con la defensa nacional, y podrán aportar su contingente para apoyar el desarrollo nacional, de acuerdo con la ley...".

Por otra parte, el artículo 163 estableció que “...La Policía Nacional es una institución estatal de carácter civil, armada, técnica, jerarquizada, disciplinada, profesional y altamente especializada, cuya misión es atender la seguridad ciudadana y el orden público, y proteger el libre ejercicio de los derechos y la seguridad de las personas dentro del territorio nacional...".

Como puede advertirse, el nuevo texto constitucional distinguió claramente entre las funciones de defensa nacional y seguridad interior y entre las instituciones destinadas a actuar en uno y otro ámbito.

En lo relativo a la defensa nacional, la Ley Orgánica de la Defensa Nacional ${ }^{112}$ estableció en su artículo 3, respecto del Presidente de la República, a quien asignó el carácter de "...máxima autoridad de las Fuerzas Armadas..." que "...Sus funciones constitucionales, en los aspectos político-administrativos, las implementará a través del Ministerio de Defensa Nacional; y, en los aspectos militar-estratégicos, con el Comando Conjunto, sin perjuicio de que las ejerza directamente...".

El artículo 4 le asignó, en caso de inminente agresión externa o guerra internacional, la dirección política de la guerra, facultándolo a delegar el mando y conducción militarestratégico en el Jefe del Comando Conjunto de las Fuerzas Armadas.

Cabe señalar, no obstante, que la exclusión del Ministerio de Defensa de las cuestiones técnico-militares no es absoluta.

En efecto, el artículo 8 definió al Ministerio de Defensa Nacional, como “...el órgano político, estratégico y administrativo de la Defensa Nacional...".

Por otra parte, los artículos 10, por un lado, relativo a atribuciones y obligaciones del Ministro de Defensa Nacional y 16, correspondiente a las principales atribuciones y deberes del Comando Conjunto de las Fuerzas Armadas, distribuyeron las competencias entre uno y otro órgano, sin asignar al último la totalidad de las facultades en lo relativo a

111 CONSTITUCIÓN DE LA REPÚBLICA DE ECUADOR sancionada en 2008, Registro Oficial, Quito, 20 de octubre de 2008.

112 Ley № 74 ORGÁNICA DE LA DEFENSA NACIONAL, Registro Oficial, Quito, 19 de enero de 2007. 
los aspectos técnicos y operativos de la defensa.

Cabe señalar que el artículo 15 estableció que el Comando Conjunto de las Fuerzas Armadas “...es el máximo órgano de planificación, preparación y conducción estratégica de las operaciones militares y de asesoramiento sobre las políticas militares, de guerra y de defensa nacional...".

Así, conforme a los artículos 15 y 16, el Comando Conjunto posee las atribuciones fundamentales en cuanto a la conducción operativa y al diseño de fuerzas a través del planeamiento estratégico militar, pero en este último caso se requiere aprobación y elevación a través del Ministerio de Defensa. Debe elaborar los anteproyectos presupuestarios correspondientes al referido Comando, y resolver previamente sobre los anteproyectos presupuestarios elevados por cada una de las Fuerzas Armadas; pero el Ministerio de Defensa está facultado para conocer y resolver sobre tales anteproyectos.

También el ministerio posee facultades en materia sustantiva, como dirigir la política de defensa nacional y elaborar la directiva de defensa militar. Cabe señalar, por otra parte, que conforme estableció el artículo 20, la función del Jefe del Comando Conjunto de informar y asesorar al Presidente de la República sobre los aspectos relacionados con la Seguridad Nacional debe ser ejercida a través del ministro de Defensa Nacional.

No obstante, preciso es tener en cuenta que las tres fuerzas armadas constituyen "los órganos operativos principales del Comando Conjunto de las Fuerzas Armadas" y dependen de éste a los efectos operativos (artículo 25), bien que, a los efectos administrativos dependen del Ministerio (artículo 10, inciso a).

También es preciso señalar que la Ley de Seguridad Pública y del Estado ${ }^{113}$ estableció un "Sistema de Seguridad Pública y del Estado" basado en un concepto de "seguridad integral" de significativa amplitud. Se distinguió, además, en materia de órganos ejecutores, entre defensa, orden público, y prevención y detección de riesgos, quedando a cargo de la primera los Ministerios de Defensa, Relaciones Exteriores y las Fuerzas Armadas (artículo 11).

Cabe destacar lo dispuesto por la reforma constitucional aprobada por la Asamblea Nacional el 3 de diciembre de $2015^{114}$ que, en lo relativo a la misión de las Fuerzas Armadas, sustituyó el segundo inciso del artículo 158 del siguiente modo “...Las Fuerzas Armadas tienen como misión fundamental la defensa de la soberanía e integridad territorial y complementariamente, apoyar en la seguridad integral del Estado de conformidad con la ley...". Una reforma similar fue realizada en la Ley de Seguridad Pública y del Estado ${ }^{115}$.

El sucesor de Correa, Lenin Moreno Garcés, cuestionó diversos aspectos de la política de Correa.

113 LEY DE SEGURIDAD PÚBLICA Y DEL ESTADO, Registro Oficial, Quito, 28 de septiembre de 2009.

114 ENMIENDAS A LA CONSTITUCIÓN DE LA REPÚBLICA DEL ECUADOR DE 2015, Registro Oficial, Quito, 21 de diciembre de 2015.

115 LEY REFORMATORIA A LA LEY DE SEGURIDAD PÚBLICA Y DEL ESTADO, Registro Oficial, Quito, 9 de junio de 2014. 
Debe destacarse la disolución de la Secretaría de Inteligencia, primer organismo civil de inteligencia, creado en el gobierno de Correa, a quien se imputaron actos de involucramiento en política partidista, a través del Decreto № $526 / 2018^{116}$, y su reemplazo por el Centro de Inteligencia Estratégica (CIES).

Por otra parte, Moreno designó como ministro de Defensa -contrariando una pauta mantenida durante el extenso gobierno de Correa de designar a ministros civiles- al general de división (R.) doctor Oswaldo Jarrín, militar con una destacada trayectoria académica, que desde sus inicios hizo conocer su intención de fortalecer el rol militar en el Estado.

El nuevo ministro preparó y obtuvo la presentación de un proyecto legislativo denominado Proyecto de Código Orgánico de Seguridad del Estado, que aparece como orientado a incrementar las facultades militares en el Estado ecuatoriano.

En el proyecto en análisis se establece, bajo la autoridad del Presidente de la República, un Consejo de Seguridad del Estado.

El órgano fundamental del nuevo Sistema resulta ser -a semejanza de la antigua Ley de Seguridad Nacional- el órgano de apoyo del Consejo de Seguridad del Estado (artículo 14) con facultades de coordinación de las recomendaciones que debe hacer el Consejo al Presidente de la República, y de seguimiento y evaluación de las decisiones del Consejo, sugerir al Presidente la convocatoria del Consejo cuando la situación lo amerite, actuar como Secretaría, responsabilizarse de la gestión documental y tener bajo su custodia los archivos y documentación del Consejo, así como la información clasificada, formular y proponer políticas de Seguridad del Estado y Movilización Nacional al Consejo de Seguridad del Estado, para su validación y posterior aprobación por el Presidente de la República, entre otros aspectos.

El proyecto agrupa tres funciones estatales diversas: la defensa nacional, la seguridad interior y la protección civil, bajo estructuras y conceptos de carácter militar que no dan cuenta de las diferencias existentes entre ellas, fundamentalmente la defensa nacional y la seguridad interior.

En definitiva, analizando la organización y características generales de la defensa ecuatoriana podemos destacar, por una parte, que el Comando Conjunto posee una dependencia directa respecto del Presidente de la Nación solo a los efectos operativos, dado que en otros aspectos técnicos, si bien tiene las funciones fundamentales, solo accede a la autoridad presidencial a través del ministro de Defensa, quien tiene facultades no solo administrativas sino también, aunque en mucho menor grado, en aspectos técnico militares.

En lo relativo a la amplitud del ámbito abarcado por las competencias de las fuerzas armadas, merece destacarse que las Fuerzas Armadas ecuatorianas, tradicionalmente una de las más multifuncionales de Latinoamérica, vieron limitado tal carácter por la Constitución Política de 2008. No obstante, como se ha visto, la reforma de la Ley de

116 Decreto № 526/2018, Registro Oficial, Quito, 30 de octubre de 2018, Suplemento. 
Seguridad Pública y del Estado y la reforma constitucional de 2015 han implicado desandar en parte el camino indicado.

De convertirse en ley el Proyecto de Código Orgánico de Seguridad del Estado tal involución se acentuaría significativamente, incrementándose la influencia militar en el Estado ecuatoriano.

\subsection{Bolivia}

En el caso del Estado Plurinacional de Bolivia, cabe destacar que la Nueva Constitución Política del Estado ${ }^{117}$ estableció en su artículo 246 que; “... I. Las Fuerzas Armadas dependen de la Presidenta o del Presidente del Estado y reciben sus órdenes, en lo administrativo, por intermedio de la Ministra o del Ministro de Defensa y en lo técnico, del Comandante en Jefe. II. En caso de guerra, el Comandante en Jefe de las Fuerzas Armadas dirigirá las operaciones....".

Por otra parte, la Ley Orgánica de las Fuerzas Armadas № 1405 de 1992, artículo 36, estableció el Comando en Jefe de las Fuerzas Armadas bajo directa dependencia del Presidente de la Nación como "...el más alto organismo de Mando y Decisión de carácter técnico-operativo, de permanente coordinación y dirección de las Fuerzas Armadas..."118.

Queda así patentizada la dependencia directa del Comando en Jefe respecto del Presidente de la Nación, y la limitación de la autoridad del ministro de Defensa a los aspectos administrativos.

El aludido Comando está formado por el Comandante en Jefe, la Jefatura de Estado Mayor General, la Inspectoría General, el Estado Mayor General, y el Gabinete del Comandante en Jefe (artículo 37). Conforme al artículo 39, se asignó al Comandante en Jefe rango de Ministro de Estado, y solo recibe órdenes, conforme dispone el artículo 39, del Presidente de la República.

El artículo 40 asignó al Comandante en Jefe todos los aspectos relativos al mando y la coordinación de las tres fuerzas armadas, y la planificación, la formulación de la doctrina militar, la dirección de la elaboración de los planes de campaña y el adiestramiento conjunto, la determinación del equipamiento militar más adecuado, etc.

Cabe señalar que los Comandantes Generales de Fuerza, a cuyo cargo está el mando en su Fuerza Armada respectiva, su educación, instrucción y preparación, etc., dependen del Comandante en Jefe y no del ministro de Defensa (artículo 60).

En cuanto al ministro de Defensa -que carece, como se ha visto, de autoridad sobre el Comandante en Jefe, excepto en los aspectos administrativos- es el Organismo Político y Administrativo de las Fuerzas Armadas y representante legal de la institución

117 Constitución Política del Estado, Gaceta Oficial del Estado Plurinacional de Bolivia, Edición NCPE, La Paz, 7 de febrero de 2009.

118 Ley № 1405 Orgánica de las Fuerzas Armadas, Gaceta Oficial del Estado Plurinacional de Bolivia, Edición 1769, La Paz, 18 de enero de 1993. 
Armada, ante los Poderes Públicos. Está excluido de la mayoría de las decisiones relativas a la defensa, que están reservadas al Comandante en Jefe. Cabe señalar que si bien el ministro de Defensa puede ser un funcionario civil, ello no sucede con sus subordinados directos, los Subsecretarios de Defensa, Aeronáutica y Fuerza Naval, que deben tener el carácter de oficiales militares en actividad del grado de general de división o equivalentes en las restantes Fuerzas.

Pese a la existencia de un Ministerio de Defensa, la circunstancia de hallarse este reducido a los aspectos administrativos, determina que en todos los aspectos fundamentales de la defensa las fuerzas armadas, a través del Comandante en Jefe dependan directamente del máximo nivel del Estado, ante el cual llegan unificadas en el órgano aludido.

A ello se agrega la facultad exclusiva del Comandante en Jefe de dirigir las operaciones.

Por otra parte, las fuerzas armadas bolivianas tienen un carácter marcadamente multifuncional.

Dicho carácter surge desde la misión de las Fuerzas Armadas establecida en el artículo 244 de la Constitución Política del Estado, el que al respecto estableció que “...Las Fuerzas Armadas tienen por misión fundamental defender y conservar la independencia, seguridad y estabilidad del Estado, su honor y la soberanía del país; asegurar el imperio de la Constitución, garantizar la estabilidad del Gobierno legalmente constituido, y participar en el desarrollo integral del país...".

En materia específica de seguridad interior, función en la que las Fuerzas Armadas participan " ...a requerimiento del Poder Ejecutivo y de acuerdo a la Constitución Política del Estado..." (artículo $6^{\circ}$, inciso g) establece el artículo $8^{\circ}$ que el Presidente dispondrá el empleo de las Fuerzas Armadas para "...en lo interno, mantener el orden público, cuando las instituciones constituidas para este fin, resultaren insuficientes..." disposición que aparece como adecuada.

En definitiva, la amplitud de la misión de las fuerzas armadas, su dependencia directa respecto del Órgano Ejecutivo en múltiples aspectos, la limitación de las facultades del ministro de Defensa a aspectos fundamentalmente administrativos, las múltiples facultades del órgano comandante en jefe entre otros aspectos ya señalados precedentemente, hacen difícil en el caso boliviano el ejercicio de la conducción política de la defensa.

Se debe señalar no obstante que durante la prolongada gestión del presidente Evo Morales el puesto de ministro de Defensa estuvo a cargo de ministros civiles.

El golpe de Estado producido en Bolivia (20 de octubre-10 de noviembre de 2019) constituyó una cabal demostración de la endeblez institucional de Bolivia y de la inexistencia de gobierno político de la defensa en dicho país, que el mandatario depuesto pretendió sustituir procurando la adhesión de las Fuerzas Armadas y de la Policía a su 
proyecto político, sin resultados.

\subsection{México}

En Estados Unidos Mexicanos las funciones de las Fuerzas Armadas son amplias.

Conforme estableció la Constitución de $1917^{119}$ modificada, es misión de las Fuerzas Armadas la seguridad interior y la defensa exterior del Estado (artículo 89, inciso VI).

Por otra parte, las funciones del Ejército y de la Fuerza Aérea incluyen la defensa de la integridad, la independencia y la soberanía de la Nación, así como garantizar la seguridad interior; auxiliar a la población civil en caso de necesidades públicas; realizar acciones cívicas y obras sociales que tiendan al progreso del país.

En caso de desastre, prestar ayuda para el mantenimiento del orden, auxilio de las personas y sus bienes, y la reconstrucción de las zonas afectadas (Ley Orgánica del Ejército y la Fuerza Aérea ${ }^{120}$, artículo 1).

Por su parte, la Armada mexicana tiene por función emplear el poder naval de la Federación para la defensa exterior y coadyuvar en la seguridad interior del país, cooperar en el mantenimiento del orden constitucional del Estado mexicano, así como las funciones de policía naval y aquellas administrativas de todo tipo vinculadas con la navegación y el ámbito marítimo. (Ley Orgánica de la Armada de México ${ }^{121}$, artículos 1 y 2).

En Estados Unidos Mexicanos no existe un Ministerio de Defensa, sino una Secretaría de Defensa Nacional de la que dependen el Ejército y la Fuerza Aérea, y una Secretaría de Marina, de la que depende la Armada, cuyos titulares deben tener estatutariamente la condición de militares del máximo grado, siendo también militares todos los órganos previstos en las Leyes Orgánica del Ejército y la Fuerza Aérea Mexicanos y Orgánica de la Armada de México. Se trata, en definitiva, de ministerios militares, expresión característica de la autonomía militar en Latinoamérica, subsistentes aún en la región, en México y en Guatemala.

Como ha sido visto precedentemente, las fuerzas armadas mexicanas tienen carácter multifuncional, con amplia injerencia en la seguridad interior, en actividades administrativas propias de su ámbito, y en acción cívica, entre otros aspectos.

La Ley de Seguridad Nacional122 estableció un mecanismo de coordinación y

119 Constitución Política de Estados Unidos Mexicanos, Diario Oficial de la Federación, México D.F., 5 de febrero de 1917. V. asimismo Constitución Política de Estados Unidos Mexicanos, Diario Oficial de la Federación, México D.F., septiembre de 2014, y Constitución Política de Estados Unidos Mexicanos, con reformas, Diario Oficial de la Federación, México D.F. 6 de marzo de 2020.

120 Ley Orgánica del Ejército y Fuerza Aérea, Diario Oficial de la Federación, México D.F., 26 de diciembre de 1986, última reforma Diario Oficial de la Federación, México D.F., 21 de junio de 2018.

121 Ley Orgánica de la Armada de México, Diario Oficial de la Federación, México D.F., 30 de diciembre de 2002, con reformas publicadas en el Diario Oficial de la Federación, México D.F., 31 de diciembre de 2012.

122 Ley de Seguridad Nacional, Diario Oficial de la Federación, México D.F., 31 de enero de 2005. Reformas 
planificación que incluye la seguridad externa, la seguridad interna, y aspectos políticos, en el que participan los secretarios aludidos.

De las muy diversas funciones de las Fuerzas Armadas mexicanas ajenas a la defensa, la seguridad interna ha sido la más importante.

La actividad de las Fuerzas Armadas mexicanas en materia de seguridad interior ha sido intensa. La sanción de la Ley de Seguridad Interior ${ }^{123}$, contribuyó a incrementar y hacer permanente tal actividad. No obstante, la referida ley fue declarada inconstitucional por la Corte Suprema de Justicia de México ${ }^{124}$.

Aunque el involucramiento de las Fuerzas Armadas mexicanas en seguridad interior reconoce tempranos como la denominada "guerra sucia" en los 60 y $70^{125}$ fue a partir de 2006, en la presidencia de Felipe Calderón, en el marco de la denominada "guerra contra el narcotráfico" que las fuerzas armadas, ya profundamente involucradas en actividades de seguridad interior, comenzaron a desempeñar un rol central en la lucha contra el delito organizado en el país, alcanzando un despliegue de 50.000 hombres con esa finalidad. Esta actividad llevó a serios cuestionamientos ${ }^{126}$ en materia de derechos humanos ${ }^{127}$ de diversas fuentes ${ }^{128} 129$, así como a un significativo crecimiento de la cifra de homicidios en México, que se mantiene hasta el presente.

Pese a las expectativas de cambios sustanciales tras la asunción del nuevo gobierno encabezado por Andrés Manuel López Obrador -quien durante la campaña electoral criticara la violencia y planteara la necesidad de desmilitarizar el país y crear una fuerza policial profesional ${ }^{130}$ - el nuevo mandatario presentó, poco tiempo antes de asumir, un denominado Plan Nacional de Paz y Seguridad, en el que se contempló reemplazar a la Policía Federal por una Guardia Nacional, dependiente de la SEDENA -órgano de dirección

publicadas en el Diario Oficial de la Federación, México D.F., 26 de diciembre de 2005.

123 Ley de Seguridad Interior, Diario Oficial de la Federación, México D.F., 21 de diciembre de 2017.

124 Sentencia de la Corte Suprema de México en la Acción de Inconstitucionalidad 6/2018 y sus acumuladas 8/2018, 9/2018, 10/2018 y 11/2018, Diario Oficial de la Federación, México D.F., 30 de mayo de 2019.

125 The National Security Archive. Informe Documental sobre 18 años de 'Guerra Sucia' en México, Washington, 2006 [En línea] Consultado el 15 de marzo de 2020, disponible en https://nsarchive2.gwu. edu//NSAEBB/NSAEBB180/index2.htm

126 SUÁREZ Enríquez, Ximena. Overlooking Justice. Human Rights Violations Committed by Mexican Soldiers against Civilians are Met with Impunity. Washington Office on Latin America, Washington, noviembre de 2017, p. 8; Human Rights Watch, Informe Anual 2018, México, New York, 2018 [En línea]Consultado el 30 de junio de 2019, disponible en https://www.hrw.org/es/world-report/2018

127 Special Rapporteur on torture and other cruel, inhuman or degrading treatment or punishment, Human Rights Council, General Assembly, United Nations, Juan E. Méndez, Mission to Mexico, Organización de las Naciones Unidas, New York, 29 de diciembre de 2014, A/HRC/28/68/Add.3.

128 Open Society Foundation. Undeniable Atrocities. Confronting Crimes Against Humanity in Mexico. New York, 2016 [En línea] Consultado el 15 de marzo de 2020, disponible en https://www.opensocietyfoundations. org/sites/default/files/undenialble-atrocities-2nd-edition-20160808.pdf

129 Human Rights Watch. Informe Anual 2018. Loc. Cit. [En línea] Consultado el 15 de octubre de 2019.

130MADRAZO Lajous, Alejandro. El desvarío histórico de la Guardia Nacional de Andrés Manuel López Obrador, New York Times en español, [En línea]Consultado el 12 de octubre de 2019, disponible en https://www. nytimes.com/es/2018/11/28/opinion-lopez-obrador-guardia-nacional/ 
del Ejército-y formada, estructurada y organizada por las Fuerzas Armadas, otorgándosele estado y disciplina militar, debiendo estar integrada por personal de la Policía Federal cuya desaparición se proyectó- y de las Policías Naval y Militar, así como por personal reclutado que se incorporaría ${ }^{131}$.

Los cuestionamientos que experimentó este proyecto determinaron que experimentara una reformulación durante el trámite en el Congreso del proyecto de ley que contenía las reformas constitucionales que brindarían base constitucional al futuro proyecto de ley de creación de la Guardia Nacional.

Así, tras sufrir sustanciales reformas en el Senado, se contempló la dependencia de la Guardia Nacional de la Secretaría de Seguridad Pública, la que debería formular la estrategia que regiría en la materia, estableciendo que el cuerpo tendría naturaleza civil, y que se regiría por una doctrina de carácter policial, debiendo los delitos que cometiera en ejercicio de su función ser juzgados por la justicia civil. También se previó que por cinco años el presidente podría disponer de las Fuerzas Armadas para tareas de seguridad pública, con carácter excepcional.

No obstante, cabe señalar que como consecuencia desapareció la Policía Federal, institución de policía civil cuya creación pareció en su momento la respuesta más consistente a las problemáticas representadas por la inseguridad y el delito organizado y que si presentaba deficiencias, la respuesta más adecuada parecía ser su depuración, profesionalización, perfeccionamiento y fortalecimiento.

Lejos de ello, se la sustituyó por una nueva institución que, por más que se la proclamó civil y bajo dependencia civil, está sujeta a fuerte impronta militar, brindada por su integración por personal, además del proveniente de la antigua Policía Federal, de la Policía Militar y de la Policía Naval, además de otorgársele reglamentos, estructura y disciplina militares, debiéndose señalar que durante el período de cinco años que se estableció para el abandono por parte de las Fuerzas Armadas de sus funciones en seguridad pública, deberían participar, además de la Secretaría de Seguridad Pública, las Secretarías de Defensa -perteneciente al Ejército- y de la Marina -perteneciente a la Armada- en el establecimiento de su estructura jerárquica, sus regímenes de disciplina, de cumplimiento de responsabilidades y de tareas, como también de servicios, así como para la instrumentación de sus normas de ingreso, educación, capacitación, profesionalización, ascensos y prestaciones, que podrán estar homologados en lo conducente a las disposiciones aplicables en la fuerza armada permanente.

Por otra parte, como jefe de la nueva Fuerza ha sido designado un oficial militar, el general Luis Rodríguez Bucio.

Han sido sancionados sucesivamente el Decreto Legislativo por el cual el Congreso aprobó las reformas constitucionales requeridas para la posterior sanción de la Ley de

131 LÓPEZ Obrador, Andrés Manuel. Plan Nacional de Paz y Seguridad 2018/2024, Transición México 20182024, Ciudad de México, 2018. 
creación de la Guardia Nacional ${ }^{132}$ (marzo de 2019), la Ley de la Guardia Nacional|133, la Ley Reformatoria de la Ley General del Sistema Nacional de Seguridad Pública ${ }^{134}$, la Ley Nacional sobre el Uso de la Fuerza ${ }^{135}$, y la Ley Nacional sobre el Registro de Detenciones ${ }^{136}$ (mayo de 2019) así como el Reglamento de la Ley de la Guardia Nacional ${ }^{137}$ (junio de 2019).

En definitiva, es difícil no prever la persistencia e incluso el incremento de la violencia que hoy caracteriza a México el aumento de la influencia política de sus Fuerzas Armadas, y el progresivo debilitamiento de las instituciones democráticas mexicanas.

Cabe señalar, asimismo, que además el nuevo gobierno mexicano ha suprimido al clásico organismo de inteligencia civil mexicano, el Centro de Investigación y Seguridad Nacional (CISEN) que dependía de la Secretaría de la Gobernación (SEGOB) y creado un nuevo organismo civil de inteligencia, el Centro Nacional de Inteligencia (CNI), dependiente de la Secretaría de Seguridad Pública y Protección Ciudadana, cuyas funciones, conforme al nuevo texto de la Ley Orgánica de la Administración Pública Federal138, Artículo 30 bis, están orientadas a la información de seguridad pública y nacional, así como del ámbito criminal y preventivo.

Cabe señalar que la creación del nuevo organismo hace desaparecer las limitadas facultades de coordinación que reconocían al CISEN la Ley de Seguridad Nacional y especialmente el Reglamento de Coordinación de Acciones Ejecutivas para la Seguridad Nacional ${ }^{139}$.

A diferencia de lo que sucedía con el antiguo CISEN, donde la generalidad de las conducciones fueron civiles, cabe señalar que el Director del nuevo organismo es un militar, el general de división (DEM) Ret. Audomaro Martínez Zapata.

Es inevitable ver en esta nueva circunstancia un nuevo incremento de la influencia militar en México, al desaparecer un tradicional organismo civil de inteligencia que, dentro de la falta de auténtica coordinación en la materia que caracterizaba a México, dada la autonomía reconocida a las Fuerzas Armadas y a sus organismos de inteligencia, admitía

132 Decreto por el que se reforman, adicionan y derogan diversas disposiciones de la Constitución Política de los Estados Unidos Mexicanos, en materia de Guardia Nacional. Diario Oficial de la Federación, 26 de marzo de 2019.

133 Decreto por el que se expide la Ley de la Guardia Nacional, Diario Oficial de la Federación, México D.F., 27 de mayo de 2019.

134 Decreto por el que se reforman, adicionan y derogan diversos artículos de la Ley General del Sistema Nacional de Seguridad Pública. Diario Oficial de la Federación, México D.F., 27 de mayo de 2019.

135 Decreto por el que se expide la Ley Nacional sobre el Uso de la Fuerza. Diario Oficial de la Federación, México D.F., 27 de mayo de 2019.

136 Decreto sobre LINEAMIENTOS para el funcionamiento, operación y conservación del Registro Nacional de Detenciones. Diario Oficial de la Federación, México D.F., 22 de noviembre de 2019.

137 Reglamento de la Ley de la Guardia Nacional. Diario Oficial de la Federación, México D.F., 22 de noviembre de 2019.

138 Ley de Reformas a la Ley Orgánica de la Administración Pública Federal. Diario Oficial de la Federación, México D.F., 30 de noviembre de 2018.

139 Reglamento de Coordinación de Acciones Ejecutivas para la Seguridad Nacional, Diario Oficial de la Federación, México D.F., 29 de noviembre de 2006. 
cierta preeminencia y limitadas facultades de coordinación al CISEN, jerarquizado por su inclusión, con un capítulo especial, en la Ley de Seguridad Nacional.

La desaparición del CISEN, reemplazado por un nuevo organismo carente de las facultades del anterior, sin ninguna disposición expresa relativa a controles, alegadamente para concluir con el espionaje político que lo caracterizó, pero manteniendo el mismo personal e inclusive a varios de sus directivos y coordinadores ${ }^{140}$ no aparece como un gesto destinado a mejorar la institucionalidad en materia de inteligencia.

\subsection{Uruguay}

El 9 de febrero de 2010, tras largo debate que involucró a sectores académicos, el Congreso de la República Oriental del Uruguay sancionó la Ley $N^{\circ} 18.650^{141}$ Ley Marco de Defensa Nacional, que implicó un cambio importante respecto del sistema preexistente, caracterizado por un conjunto de normas entre las que sobresale el Decreto-Ley $\mathrm{N}^{\circ}$ $14.157 / 74^{142}$ Ley Orgánica Militar, dictada por el gobierno de facto encabezado por Juan María Bordaberry, caracterizada por asignar al Ministerio de Defensa exclusivamente los aspectos administrativos, reservándose las Fuerzas Armadas los aspectos técnicooperativos y de planificación, así como la conducción operativa.

De todos modos, la circunstancia de tratarse de una Ley Marco, que estableció aspectos generales, destinada a ser complementada por una futura Ley Orgánica del Ministerio de Defensa Nacional -aún no sancionada- y por reglamentaciones, llevan a pensar que aún algunas cuestiones de importancia para nuestro análisis están pendientes de resolución, y que la Ley Marco constituye un cuerpo normativo de transición.

La Ley Marco definió en su artículo $1^{\circ}$ a la Defensa Nacional como “...el conjunto de actividades civiles y militares dirigidas a preservar la soberanía y la independencia de nuestro país, a conservar la integridad del territorio y de sus recursos estratégicos, así como la paz de la República, en el marco de la Constitución y las leyes; contribuyendo a generar las condiciones para el bienestar social, presente y futuro de la población..."143.

Se trata de una definición de cierta amplitud, que además del concepto tradicional del término, incluyó la seguridad interior, dejando además espacio para otras actividades ajenas al aludido concepto tradicional.

Cabe señalar, no obstante, que en materia de política militar de defensa prescribió el artículo $5^{\circ}$ que “... La política militar de defensa establecerá la doctrina del empleo de los medios militares que aseguren la integridad territorial del país y el libre ejercicio de los derechos de jurisdicción y de soberanía en los espacios terrestre, marítimo y aéreo del

140 BADILLO, Miguel. Centro de Inteligencia opera con 99\% de personal del Cisen, 4 de marzo de 2019, Contralínea, Ciudad de México, [En línea] Consultado el 15 de noviembre de 2019, disponible en: https:// www.contralinea.com.mx/archivo-revista/2019/04/03/centro-de-inteligencia-opera-con-99-de-personaldel-cisen/

141 Ley № 18650, IMPO, Montevideo, 8 de marzo de 2010.

142 Decreto Ley 14157, IMPO, Montevideo, 5 de marzo de 1974.

143 Ley № 18650. Loc. Cit. 
Estado uruguayo. Asimismo, determinará la adecuada y eficaz preparación para enfrentar una agresión militar externa..." ${ }^{144}$.

Cabe concluir, en definitiva, que la agresión militar externa contra la integridad territorial del país y el libre ejercicio de los derechos de jurisdicción y soberanía en los espacios terrestre, marítimo y aéreo, habrán de constituir el objetivo fundamental de la política militar de defensa uruguaya.

En materia de distribución de competencias, el artículo $8^{\circ}$ asignó al Presidente de la República, actuando con el ministro de Defensa Nacional, con los Ministros respectivos o con el Consejo de Ministros “...A) Determinar la política de Defensa Nacional y sus objetivos. B) Dirigir la Defensa Nacional. C) Ejercer el Mando Superior de las Fuerzas Armadas. D) Adoptar las medidas pertinentes para solucionar las situaciones de crisis que afecten a la Defensa Nacional. E) Ejercer la conducción político-estratégica de la Defensa Nacional. F) Establecer las directivas para las negociaciones exteriores que afecten a la política de Defensa Nacional..." ${ }^{145}$.

Cabe señalar que la ley dispuso (artículo 10) la creación de un Consejo de Defensa Nacional (CODENA) como órgano asesor y consultivo del Presidente de la República en materia de defensa integrado por el Presidente de la República como presidente, y los ministros de Defensa Nacional, del Interior, de Relaciones Exteriores y de Economía y Finanzas, destinado a reunirse por convocatoria del Presidente de la República, estableciéndose que además de los citados, miembros permanentes, podrían ser convocados entre otros, incluyendo legisladores, jueces y funcionarios, el Jefe del Estado Mayor de la Defensa, a los Comandantes en Jefe de la Armada, del Ejército y de la Fuerza Aérea.

Como puede advertirse, la composición ordinaria del CODENA es exclusivamente de aquellos ministros de mayor vinculación con la problemática de la defensa.

Es función del CODENA asesorar (artículo 12) sobre la Defensa Nacional teniendo entre sus cometidos las amenazas que pudieran poner en riesgo la soberanía e independencia de la República, así como afectar gravemente los intereses nacionales, proponiendo en tales casos las medidas y/o acciones que se estimaran necesarias para su resolución; y analizar y proponer las hipótesis de conflicto, sugiriendo en estos casos la aprobación de los planes y la coordinación de las acciones necesarias para la defensa, y realizar propuestas sobre asuntos relacionados con la defensa que, por afectar a varios organismos del Estado, requirieran un tratamiento conjunto.

Estableció, además, el artículo 13 una Secretaría Permanente destinada a funcionar en el ámbito del Ministerio de Defensa.

Como puede advertirse, el órgano de determinación de amenazas y de asesoramiento a su respecto es de naturaleza civil, sin perjuicio de que pueda requerir asesoramiento 
militar, en lo que se diferencia netamente de su predecesor COSENA.

Merece señalarse no obstante la creación, como consecuencia del Decreto $\mathrm{N}^{\circ}$ $147 / 2013^{146}$ aprobatorio del Reglamento de Organización y Funcionamiento del CODENA -que amplió sustancialmente las funciones de este órgano, particularmente en materia de política de defensa y política militar, superponiéndose en buena medida con las funciones asignadas en la Ley Marco al Ministerio de Defensa- de la Comisión Interministerial de Defensa Nacional (CIDEN), bajo dependencia de la Secretaría Permanente del CODENA, constituido por representantes de los miembros permanentes del CODENA y por representantes de otros ministerios o dependencias del Estado cuyos conocimientos o competencias se consideran de utilidad para el estudio de los asuntos específicos que hubieran de tratarse.

Cabe destacar, por otra parte, que el artículo 15 del referido Reglamento prevé que el Secretario Permanente reúna condiciones de idoneidad.

Como primer Secretario Permanente del CODENA fue designado el entonces Jefe de Estado Mayor de la Defensa, general de ejército Daniel Castellá, manteniendo su cargo militar. De ese modo, un subordinado del ministro de Defensa quedó a cargo del órgano de trabajo de un Consejo "...asesor y consultivo del Presidente de la República en materia de Defensa Nacional..." ${ }^{147}$ (artículo 1ㅇ) que cuenta entre sus funciones las de "...aprobar los planes y coordinar las acciones necesarias para la Defensa..." ${ }^{148}$.

Consecuencia de los factores expuestos fue la aprobación por el Decreto № $105 / 2014^{149}$ de la Política de Defensa Nacional, elaborada por el CODENA, asignándose a la propuesta elaborada por tal órgano -cuyo Secretario Permanente era, a la sazón, el Jefe de Estado Mayor de la Defensa, general de ejército Milton Ituarte- conforme surge de la motivación del decreto, el carácter de documento de más alto nivel de gobierno en la materia.

En definitiva, puede advertirse que en Uruguay la elaboración de la política de defensa está a cargo, en realidad, del Jefe de Estado Mayor de la Defensa más que del ministro de Defensa.

En otro orden de ideas, la Ley Marco asignó asimismo al Ministerio de Defensa Nacional (artículo 14) “... la conducción política de aquellas áreas de la Defensa Nacional que las leyes y el Poder Ejecutivo en el marco de sus facultades determinen y en particular todo lo relacionado con las Fuerzas Armadas..." 150 disponiéndose además que el ministro tuviera a su cargo, entre otras funciones, las de actuar con el Presidente de la República en todo lo inherente a la Defensa Nacional; la preparación, la dirección, el ordenamiento y la ejecución de la política de Defensa Nacional; y la obtención y la gestión de los recursos humanos y materiales para ello.

146 Decreto № 147/2013, IMPO, Montevideo, 20 de mayo de 2013.

147 Decreto № 147/2013. Loc. Cit.

148 Ibíd.

149 Decreto № 105/2014, IMPO, Montevideo, 30 de mayo de 2014.

150 Ley № 18650. Loc. Cit. 
Además de estas funciones, por cierto significativas, el artículo 15 asignó al Ministerio de Defensa las funciones relativas al ejercicio de la "...gestión administrativa, financiera, jurídica y establecer los criterios de gestión de los recursos humanos...ejercer la dirección y la supervisión de todas las actividades que cumplan las Fuerzas Armadas, siguiendo los lineamientos que se establezcan al respecto por el Mando Superior..."; también la determinación de la orientación y el delineamiento de la formación de las Fuerzas Armadas ${ }^{151}$.

Con relación al Jefe del Estado Mayor de la Defensa, fue dispuesto que dependería directamente del ministro de Defensa Nacional; dependiendo a su vez de dicho Jefe, el Mando General de las operaciones conjuntas o conjuntas combinadas, estableciéndose un Jefe de Operaciones, que representaría el Nivel Estratégico Operacional junto con los Comandantes de Mandos Conjuntos que se creen para el cumplimiento de los Planes Militares de la Defensa. También se estableció la dependencia respecto del Jefe del Estado Mayor de la Defensa, del Sistema Nacional de Operaciones de la Paz (SINOMAPA).

Fue, asimismo, establecido que integrarían el Ministerio de Defensa la Armada Nacional, Ejército Nacional y Fuerza Aérea Uruguaya, como organismos que ejecutarían las tareas necesarias para cumplir los cometidos asignados atinentes a la defensa.

Cabe destacar que no se advierten restricciones a las facultades de supervisión y conducción del ministro respecto de las fuerzas armadas.

No obstante, si bien el jefe del referido Estado Mayor depende directamente del ministro, no se advierte que éste cuente con órganos o instancias de asesoramiento que le permitan ejercer sus funciones de conducción y control. Es decir, que en aspectos técnicomilitares pareciera que el ministro debe reposar exclusivamente en el asesoramiento del Estado Mayor de la Defensa.

Cabe señalar, además, que la Ley Marco se refiere a las Fuerzas Armadas como responsables de la ejecución de las actividades militares de la Defensa Nacional (artículo 17), disponiendo el artículo 18 que “...Su cometido fundamental es la defensa de la soberanía, la independencia e integridad territorial, la salvaguarda de los recursos estratégicos del país que determine el Poder Ejecutivo y contribuir a preservar la paz de la República en el marco de la Constitución y las leyes...sumando entonces a la defensa, funciones de contribución a la seguridad interior..." ${ }^{152}$.

Cabe señalar asimismo lo dispuesto por el artículo 20, en cuanto a que "...en tiempo de paz y bajo la autorización expresa del Ministro de Defensa Nacional, podrán prestar servicios o colaboración en actividades que por su especialidad, relevancia social o conveniencia pública les sean solicitadas y sin que ello implique detrimento en el cumplimiento de su misión fundamental..."153.

151 lbíd.

152 Ley № 18.650. Loc. Cit.

153 lbíd. 
Similar principio se incluye en el artículo 23 del capítulo 2 dedicado a misiones en el exterior, aspecto importante para las Fuerzas Armadas uruguayas, que dedican a ellas una proporción muy significativa de los efectivos de que disponen.

En conclusión, resulta evidente que la Ley Marco ha representado un avance muy significativo desde el punto de vista de la conducción política de la defensa, respecto de las normas que la antecedieran, estableciéndose un Ministerio de Defensa con facultades suficientes, bajo cuya dependencia, el Estado Mayor de la Defensa cuenta con las atribuciones necesarias para el establecimiento del accionar conjunto, aspecto favorecido por otras disposiciones de la ley.

Por otra parte, la falta de sanción de la anunciada Ley Orgánica del Ministerio de Defensa y el dictado y aplicación del Decreto № 147/2003 -con el resultado de la transferencia de facultades legalmente correspondientes al ministerio a un órgano controlado por el Jefe del Estado Mayor de la Defensa- ha tenido como resultado un sensible retroceso en el camino iniciado.

Se debe señalar como un logro importante para el control civil la sanción de la Ley № $19.696^{154}$ sobre el sistema Nacional de Inteligencia de Estado, norma que reorganiza el aludido sistema, creando un organismo civil de inteligencia estratégica como coordinador de los órganos y organismos que lo integran, de carácter militar y policial, estableciéndose controles.

Se trata de la Secretaría de Inteligencia Estratégica del Estado (SIEE) bajo dependencia del Órgano Ejecutivo, con facultades de formulación del Plan Nacional de Inteligencia para su aprobación por el referido órgano, y de coordinación, producción de inteligencia estratégica, producción de inteligencia y contrainteligencia respecto de amenazas.

Cabe señalar que fue designado al frente del nuevo organismo un oficial militar, el general del aire Washington Martínez.

Se implementaron además controles sobre la actividad de inteligencia, requiriéndose aprobación judicial para la realización de acciones invasivas de la privacidad de los habitantes, creándose además una comisión bicameral parlamentaria de control, con facultades más significativas que las que poseen sus similares de la región.

Cabe señalar que habiendo asumido el 10 de marzo de 2020 el nuevo gobierno encabezado por el mandatario centrista Luis Lacalle Pou, este designó al frente de la SIEE a un abogado y profesor colaborador suyo, Álvaro Garcé, quien afirmó su propósito de centrar la labor del sistema de inteligencia uruguayo en la lucha contra el delito organizado ${ }^{155}$.

El nuevo presidente presentó un "Anteproyecto de Ley de Urgente Consideración

154 Ley № 19696, IMPO, Montevideo, 7 de noviembre de 2018.

155 BARRENECHE, Eduardo. Crimen Organizado en la mira del nuevo sistema de Inteligencia estatal. El País, Montevideo 5 de Enero 2020 [En línea] Consultado el 15 de marzo de 2020. Disponible en: https://www. elpais.com.uy/informacion/politica/crimen-organizado-mira-nuevo-sistema-inteligencia-estatal.html 
denominado Uruguay Seguro, Transparente y de Oportunidades"156, que en materia de inteligencia, propuso el fortalecimiento de las facultades para conducción del Sistema de Inteligencia por parte de la SIEE, y la creación en ésta del cargo de Subdirector.

Por otra parte, circunstancias desde el punto de vista de las relaciones civilesmilitares han acaecido durante el mandato del presidente Tabaré Vázquez, representadas por la crítica pública por parte del Comandante en Jefe del Ejército Uruguayo, general de ejército Guido Manini Ríos, al proyecto oficial de reformar el sistema de pensiones de las Fuerzas Armadas uruguayas; así como al sistema judicial uruguayo, con motivo de los juicios realizados a militares por violaciones a los derechos humanos durante la dictadura militar, hechos que determinaron su destitución ${ }^{157}$ por decisión presidencial; a lo que siguió la de su sucesor José González, el ministro de Defensa Jorge Menéndez y otros funcionarios civiles y militares ${ }^{158}$, a raíz de un proceso realizado por un Tribunal de Honor, por declaraciones formuladas en aquél admitiendo asesinatos y otros delitos, sin que ello fuera considerado lesivo al honor militar y sin que el Ministerio de Defensa formulara observación alguna.

En definitiva, el activismo puesto de manifiesto por la conducción del Ejército uruguayo en actitudes que implicaban un desafío a las autoridades electas, creó una situación dificultosa para las relaciones civiles-militares en Uruguay.

Cabrá seguir con atención la situación en el mandato del nuevo presidente uruguayo.

\section{Conclusiones}

En un marco de retroceso de la integración regional, de creciente polarización ideológica y de presencia, gravitación y confrontación, además de la gran potencia hemisférica de otras dos potencias extrarregionales, Latinoamérica enfrenta con evidente debilidad una verdadera encrucijada donde la paz, la cooperación y la marcha hacia el fortalecimiento del sistema democrático que la caracterizaron por tres décadas parecen en riesgo.

Dentro de esa situación un aspecto de fundamental importancia está representado por la situación de sus Fuerzas Armadas.

El panorama que presentan las Fuerzas Armadas latinoamericanas en los últimos

156 FERRÉS, Rodrigo. ANTEPROYECTO DE LEY DE URGENTE CONSIDERACIÓN URUGUAY SEGURO, TRANSPARENTE Y DE OPORTUNIDADES, Luis Lacalle Pou, Montevideo, Febrero de 2020, [En línea] Consultado el 1 de marzo de 2020, disponible en https://lacallepou.uy/anteproyectoLUC.pdf

157 MARTÍNEZ, Magdalena. El presidente de Uruguay destituye al jefe del Ejército por sus críticas a los juicios contra represores, El País, Madrid, 12 de marzo de 2019 [En línea] Consultado el 20 de diciembre de 2019, disponible en https:/elpais.com/internacional/2019/03/12/america/1552413001_068945.html

158 Tabaré Vázquez destituyó al ministro de Defensa y a la cúpula del Ejército de Uruguay , Buenos Aires, 1 de abril de 2019, [En línea] Consultado el 20 de febrero de 2020, disponible en https://www.infobae.com/ america/america-latina/2019/04/01/tabare-vazquez-destituyo-al-ministro-de-defensa-y-a-la-cupula-delejercito-de-uruguay-por-el-encubrimiento-de-un-asesinato/ 
años es, en la gran mayoría de los casos, el de un deterioro de la conducción política respecto de ellas y, como consecuencia, de una creciente autonomía; un avance de su carácter multifuncional y especialmente de su dedicación a la seguridad interior; y un crecimiento de su influencia política.

En materia de relaciones civiles-militares, cabe percibir el debilitamiento, con llamativa simultaneidad -inequívoca manifestación de causas externas- del ya endeble -en la mayoría de los casos- control civil en los países latinoamericanos. Se asignan a las Fuerzas Armadas funciones en seguridad interior en países en los cuales estaban claramente orientadas hacia la defensa; se designan oficiales militares al frente de Ministerios de Defensa y organismos de inteligencia civiles en casos en que ello no ocurría; organismos de inteligencia militares incursionan en la política de sus países.

La creciente dedicación de las Fuerzas Armadas a la seguridad interior -aspecto siempre presente en la mayor parte de la región, pero cuya gran intensidad, fuera característica de la Guerra Fría- incrementa las dificultades para el control civil en aquellos países en los cuales éste aún subsiste, así como para la vigencia de los derechos humanos, efecto este último que se deriva del empleo de fuerzas concebidas, diseñadas y preparadas para la guerra, para el mantenimiento del orden público y la represión del delito. Estos riesgos están presentes, en mayor grado, en aquellos países caracterizados precisamente por la inexistencia o debilidad del control civil ${ }^{159}$.

Resulta perceptible la similitud de la situación actual con la vigente en la materia en los comienzos de la Guerra Fría, y cabe preguntarnos acerca de una hipotética influencia en la situación descripta, de la existencia de una percepción de amenaza por parte de Estados Unidos respecto de la presencia y actividades de la Federación Rusa y de la República Popular China en Latinoamérica y, en caso afirmativo, si tal percepción de amenaza no está siendo enfrentada por Estados Unidos -con un gobierno hoy más asertivo en la defensa de los intereses inmediatos de su país- de manera similar a la empleada en la antigua Guerra Fría, es decir, impulsando la militarización y la polarización política de los países de la región.

Cabe esperar, no obstante, que la experiencia acumulada tanto por Estados Unidos como por América Latina respecto de los efectos en esta última de la Guerra Fría impedirán que ello ocurra, y que políticas más lúcidas que las implementadas en aquella oportunidad constituirán los instrumentos para resolver los conflictos que presenta la región. Pero esta apreciación, ¿̇es más que una expresión de deseos?

Lo cierto es que el debilitamiento de la integración regional y la virtual desaparición de sus aspectos políticos deja a la región privada de toda capacidad de acción política colectiva para enfrentar o atenuar los efectos en la región de la confrontación y pugna de las indicadas potencias extrarregionales.

159 UGARTE, José Manuel. Roles, influencia política y control civil de las Fuerzas Armadas en Latinoamérica. ¿Existe una relación? En caso afirmativo, ¿cuál es su intensidad? Ponencia presentada en el Congreso de Latin American Studies Association, LASA 2018, Barcelona, 2018. 
Dada la indicada situación, y desde Latinoamérica, consideramos que reafirmar y establecer, en aquellos países en los cuales no está establecida, la conducción política de la defensa, obteniendo un instrumento militar eficaz adecuado para responder a las necesidades de defensa del país, y plenamente identificado con los intereses nacionales, es el mejor medio para evitar ser objeto de alteraciones impulsadas por causas externas al país.

En efecto, contar con una adecuada capacidad de defensa -y de inteligencia- resulta hoy imprescindible si se pretende evitar o limitar los efectos de injerencias dirigidas a alistar a un país latinoamericano en conflictos que pueden no ser propios, salvo, obviamente, que la decisión adoptada libremente por el país a través de sus instituciones sea participar en ellos.

Lo contrario equivale a admitir que el país propio pueda, como sucedió en la Guerra Fría, pasar a constituir una mera ficha en un juego de grandes potencias, con sacrificio o limitación de la vigencia en él del sistema democrático y subordinación de sus intereses a otros intereses.

Al propio tiempo, la reafirmación de la plena vigencia del sistema democrático y la cooperación política para promoverla y asegurarla en la región entre los países que la integran, también contribuiría al objetivo precedentemente señalado.

La conducción política de la defensa, ¿’es un bien en sí mismo?

Ciertamente no basta con que esté establecida la conducción política de la defensa, sino que es preciso ejercerla con conocimiento y aptitud, posibilitando también la llegada y aprovechamiento del asesoramiento profesional militar, para obtener como resultado una adecuada capacidad de defensa. El caso de Argentina, que habiendo logrado el ejercicio de tal conducción, no obtuvo que ella se tradujera en el logro de una capacidad de defensa eficaz, es un ejemplo.

Sobran no obstante en el mundo los ejemplos del adecuado ejercicio de la conducción política de la defensa y del logro de una notable capacidad de defensa, preservándose y fortaleciéndose la democracia. Casos como los de Estados Unidos, Reino Unido, Francia, Canadá, Australia, Italia, República Federal de Alemania, entre otros, acreditan lo expuesto. La conducción política de la defensa es en definitiva un instrumento tanto del fortalecimiento de la democracia, como de la capacidad de defensa.

El logro de una adecuada capacidad de defensa es un bien fundamental para todo país. Pero para que una sociedad determinada pueda disfrutar de ese bien, se requiere que esa capacidad esté realmente a órdenes de la legítima conducción política de esa sociedad. con las ventajas del valor defensa, cuyo costo está plenamente justificado por el logro de la seguridad externa del país y el disfrute de su soberanía.

Latinoamérica no es una región cuyos países están mágicamente libres de conflictos externos de naturaleza militar y que por ello pueda, o deba, dedicar sus Fuerzas Armadas a tareas policiales. Contar con Fuerzas Armadas adecuadas implica contar con un poder 
disuasorio eficaz frente a posibles agresiones militares externas. La amenaza representada por el delito y particularmente el delito organizado trasnacional debe ser encarada a través de los medios adecuados: policías, fuerzas de seguridad, inteligencia criminal, inteligencia financiera.

Consideramos que la democracia es el sistema político y el modo de vida que la mayoría de los países latinoamericanos han escogido, y que su plena vigencia requiere el logro de la conducción política de la defensa. Si esto es así, los últimos años han constituido en Latinoamérica un retroceso en ese camino, que es preciso rectificar.

\section{REFERENCIAS BIBLIOGRÁFICAS}

BEN MEIR, Yehuda. Civil-Military Relations in Israel. Jaffee Center for Strategic Studies, Tel Aviv University, Columbia University Press, New York, 1999.

BUSSO, Anabella (1991). Estados Unidos y la redemocratización latinoamericana: los condicionantes externos, Revista Estudios Internacionales, Volumen 24 Número 94 Universidad de Chile, Santiago de Chile, [En línea] Consultado el 25 de mayo de 2019, disponible en https://revistaei.uchile.cl/index.php/REl/article/ download/15460/15913/

DESCH, Michael C., Civilian control of the military. The changing security environment. The John Hopkins University Press, Baltimore, 2001.

FINER, Samuel E. The man on horseback. The Role of the Military in Politics. Transaction Publishers New Brunswick and London, Fourth printing, 2006.

FITCH, John Samuel. The Armed Forces and Democracy in Latin America, The John Hopkins University Press, Baltimore \& London, 1998.

HUNTINGTON, Samuel. The soldier and the state. The Theory and Politics of Civil-Military Relations. The Belknap Press of Harvard University Press. Cambridge, Massachusetts and London, England, 1985.

LIEWEN, Edwin. Armas y política en América Latina, Sur, Buenos Aires, 1960.

MAECHLING, Charles. Contrainsurgencia: La primera prueba de fuego.: En: KLARE, Michael. y KORNBLUH, Peter Contrainsurgencia, proinsurgencia y antiterrorismo en los 80. El arte de la guerra de baja intensidad, Grijalbo, Ciudad de México, 1990.

PION-BERLIN, David y UGARTE, José Manuel. Organización de la defensa y control civil de las Fuerzas Armadas en América Latina, Buenos Aires, Jorge Baudino Editores, 2013.

PION-BERLIN, David y MARTÍNEZ, Rafael. Soldiers, politicians, and civilians, Cambridge University Press, New York, 2017. 
UGARTE, José Manuel. Una visión desde Latinoamérica de la organización de la defensa y relaciones civiles-militares. En: PION-BERLIN, David y Ugarte, José Manuel, Organización de la defensa y control civil de las Fuerzas Armadas en América Latina, Buenos Aires, Jorge Baudino Editores, 2013

UGARTE, José Manuel. Roles, influencia política y control civil de las Fuerzas Armadas en Latinoamérica. ¿Existe una relación? En caso afirmativo, ¿cuál es su intensidad? Ponencia presentada en el Congreso de Latin American Studies Association, LASA 2018, Barcelona, 2018.

UGARTE, José Manuel. Defensa indefensa, o apariencia de defensa: la política de defensa argentina; Perspectivas Revista de Ciencias Sociales (PRCS) No. 7 Enero - Junio 2019, [En línea] Consultado el 20 de septiembre de 2019. Disponible en http://hdl. handle.net/2133/15383 